\title{
Artificial photosynthesis by light absorption, charge separation, and multielectron catalysis
}

\begin{abstract}
Miloš Đokića and Han Sen Soo*ab
Our society's current energy demands are largely met by the exploitation of fossil fuels, which are unsustainable and environmentally harmful resources. However, Nature has provided us with a clean and virtually limitless alternative in the form of solar energy. This abundant resource is utilized constantly by photosynthetic organisms, which has in turn motivated decades of research in our quest to create artificial counterparts of comparable scales. In this Feature article, we will highlight some of the recent novel approaches in the field of artificial photosynthesis (AP), which we define by a more general term as a process that stores energy overall by generating fuels and chemicals using light. We will particularly emphasize on the potential of a highly modular plug-and-play concept that we hope will persuade the community to explore a more inclusive variety of multielectron redox catalysis to complement the proton reduction and water oxidation half-reactions in traditional solar water splitting systems. We discuss some of the latest developments in the vital functions of light harvesting, charge separation, and multielectron reductive and oxidative catalysis, as well as their optimization, to achieve the ultimate goal of storing sunlight in chemical bonds. Specific attention is dedicated to the use of earth-abundant elements and molecular catalysts that offer greater product selectivity and more intricate control over the reactivity than heterogeneous systems. In this context, we showcase our team's contributions in presenting a unique oxidative carbon-carbon bond cleavage reaction in aliphatic alcohols and biomass model compounds, under ambient atmospheric conditions, facilitated by vanadium photocatalysts. We offer this discovery as a promising alternative to water oxidation in an integrated AP system, which would concurrently generate both solar fuels and valuable solar chemicals.
\end{abstract}

\section{Introduction}

The "terawatt (TW) challenge" was coined in 2005 by the late Nobel laureate, Richard Smalley, to contextualize the scale of our energy requirements in the near future. ${ }^{1}$ Currently, over $80 \%$ of global energy needs are satisfied by fossil fuels, ${ }^{2}$ and the total energy demand is expected to increase by about $20 \%$ to 23 TW in $2030 . .^{3,4}$ Furthermore, fossil fuels are limited, and the additional strains from pollution and global climate change due to fossil fuel combustion has led to an impending energy and environmental crisis. ${ }^{5,6}$

Nature has provided a blueprint and inspiration for averting and overcoming these energy and pollution crises. ${ }^{3,}$ 4, 7-9 On average, solar energy reaches the Earth's surface at a rate of 120000 TW, which is at least three orders of magnitude above what the global population uses now and will need in the foreseeable future. ${ }^{3,10}$ To exploit this virtually unlimited resource, natural photosynthesis worldwide currently stores solar energy at a rate of around 120 TW. 3 , 4, 10 Photosynthetic organisms have evolved sophisticated biological processes, using exclusively earth-abundant elements

a. Division of Chemistry and Biological Chemistry, School of Physical and Mathematical Sciences, Nanyang Technological University, 21 Nanyang Link, Singapore 637371. E-mail: hansen@ntu.edu.sg; Tel: +65 65923182.

b. Solar Fuels Laboratory, Nanyang Technological University, 50 Nanyang Avenue, Singapore 639798. available in disparate ecosystems, to capture solar energy and store it in reduced carbon compounds. ${ }^{3,} 4$ In so doing, they have simultaneously achieved multiple functions that should instruct us, including the following aspects.

(i) The storage of diffuse sunlight over a panchromatic spectral range into energy dense fuels. Although solar energy is plentiful, it is distributed over a broad surface area and electromagnetic spectrum. ${ }^{3,} 4,9$ Yet photosynthetic organisms have been able to concentrate this energy into energetic small molecules.

(ii) The spatial and temporal separation of energy collection versus energy use. The available sunlight varies with the location, season, time of the day, and the weather. By storing the energy within the chemical bonds of small molecules, Nature circumvents the need to manage or match the solar flux with utilization, as usually required in photovoltaics. ${ }^{10,11}$

(iii) The one-directional multielectron charge separation across an interfacial membrane via thermodynamically and kinetically favorable and well-matched chemical processes. The chlorophyll chromophores absorb single photons and undergo single charge separation events, but are coupled with energetically downhill charge transfer reactions that kinetically outcompete undesired recombination 
processes. ${ }^{3,4,7,8}$ Natural photosynthesis operates essentially with a molecular diode.

(iv) The indirect energy storage on the reductive half-reaction in the form of partially reduced carbon (instead of nitrogen) compounds via kinetically more facile proton reduction processes. The primary light driven process in the reductive Photosystem I half-reaction is the generation of "hydride" equivalents from water to convert $\mathrm{NADP}^{+}$to $\mathrm{NADPH}$, which is subsequently employed in carbohydrate synthesis in the dark Calvin cycle. ${ }^{3,4,7,8}$ The two-electron reduction of NADP+ and subsequent reduction of $\mathrm{CO}_{2}$ are all kinetically accessible reactions with numerous stable intermediates.

(v) The concurrent generation of an oxygenic atmosphere to support their own survival and those of other aerobic organisms in an equally productive and critical oxidative half-reaction. Energy is stored during water oxidation to $\mathrm{O}_{2}$, which can subsequently be released during aerobic respiration.

Nature has thus created a self-sustaining system from which we can derive insights and adapt to our contemporary demands.

Commensurate with the scale of the TW challenge, interuniversity and even international consortiums have dedicated research efforts to the development of artificial photosynthesis $(\mathrm{AP})$, with the intention of mimicking green plants to produce solar chemicals and ultimately solar fuels. ${ }^{12}$ However, the term AP is traditionally often synonymous with solar fuels or water splitting, which may be unnecessarily restrictive. As the term suggests, AP is the invention of man-made (artificial) chemical or biological processes to harness light (photo) to produce fuels and chemicals (synthesis). To differentiate between photosynthesis and photocatalysis in this article, we will adopt a convention based on thermodynamics and kinetics. ${ }^{13}$ Photocatalysis involves light as an energy input to accelerate rates by overcoming the kinetic barrier for reactions that are already thermodynamically downhill reactions, whereas photosynthesis requires light to drive reactions that are otherwise thermodynamically uphill. In other words, we use photosynthesis to refer to redox processes that will store energy overall across two half-reactions.

Tremendous progress has been reported in the field of AP, although the research has largely focused on solar fuels production through water splitting by semiconductor materials. ${ }^{14-17}$ On the other hand, molecular systems offer the advantages of systematic ligand design and modification, better product selectivity, and more comprehensive characterization.

Inspired by natural photosynthesis, our team has adopted an engineering "plug-and-play" concept to create AP constructs based on combining the functions of individual components (Fig. 1). A number of research groups and us have been exploring a more general perspective to use light to make chemicals, beyond $\mathrm{H}_{2}$ and $\mathrm{O}_{2}$ from water splitting. In this feature article, we will focus the discussion on the specific functions of photosynthesis, which can be distilled into the following four themes.

(i) The productive absorption of sunlight, especially with panchromatic chromophores.

(ii) The effective charge separation and interfacial chemistry to achieve a more systematic flow of reducing and oxidizing equivalents.

(iii) The multielectron catalytic reduction of substrates to produce fuels.

(iv) The multielectron catalytic oxidation of substrates to produce similarly value-added chemicals other than the

\section{Artificial Photosynthesis by Light Absorption, Charge Separation, and Multielectron Catalysis}
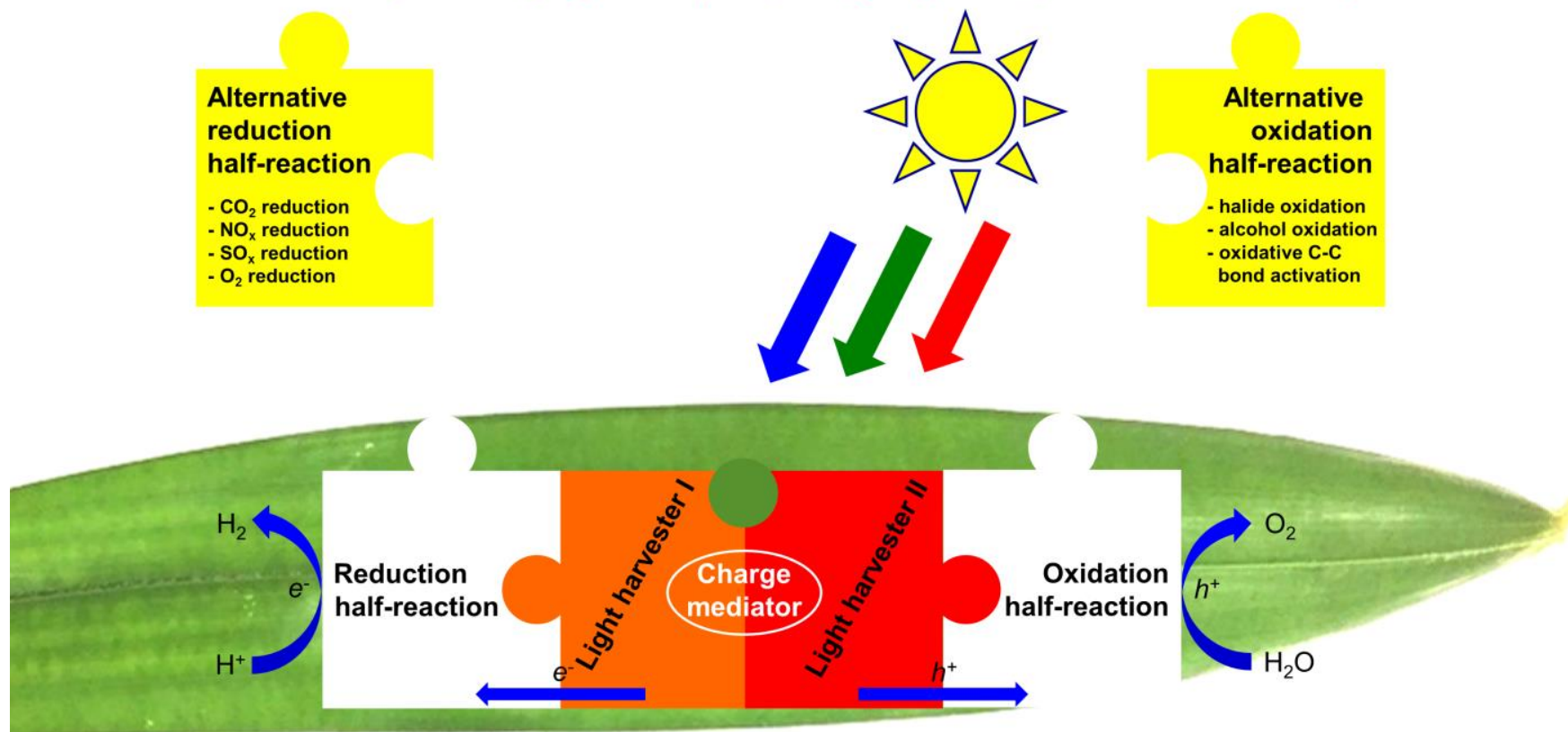

Fig. 1 Proposed general "plug-and-play" system for AP to encompass a more inclusive range of catalytic processes that can store sunlight in the form of chemical bonds in solar fuels and value-added solar chemicals. 
atmospherically abundant $\mathrm{O}_{2}$.

We will examine some of the latest research on optimizing the individual constituents of an integrated system, some of which have been assembled into AP units. This article is not intended to be a comprehensive coverage of the extensive field of AP, but will especially highlight molecular and hybrid molecular-material systems comprising exclusively earth-abundant elements.

\section{Light absorption}

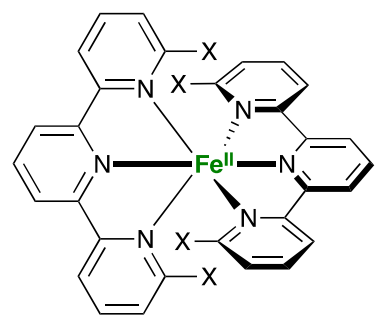

${ }^{7} \mathrm{MLCT} \tau$ up to $17.4 \mathrm{ps}$ $\mathrm{X}=\mathrm{F}, \mathrm{Cl}, \mathrm{Br}$

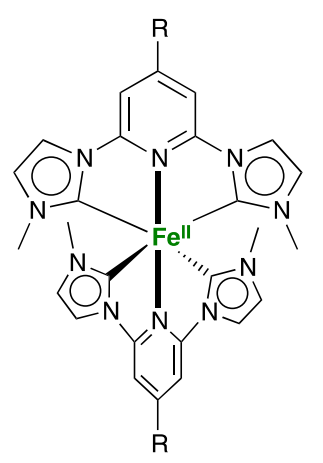

${ }^{3} \mathrm{MLCT} \tau$ up to $37 \mathrm{ps}$

$\mathrm{R}=\mathrm{H}, \mathrm{COOH}$

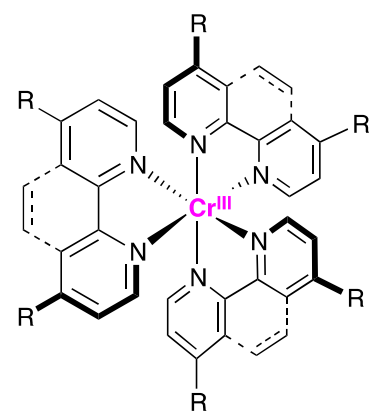

${ }^{2} \mathrm{MLCT} \tau$ up to $425 \mu \mathrm{s}$

$\mathrm{R}=\mathrm{H}, \mathrm{Ph},{ }^{t} \mathrm{Bu}, \mathrm{CO}_{2} \mathrm{CH}_{3}$

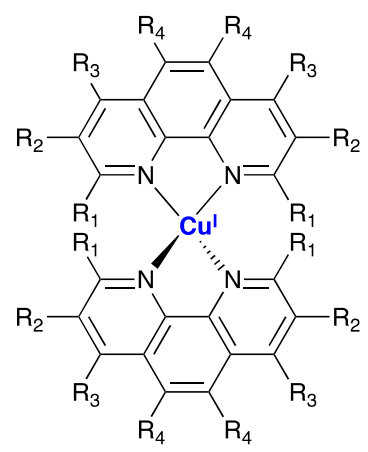

${ }^{3} \mathrm{MLCT} \tau$ up to $2.8 \mu \mathrm{s}$

$\mathrm{R}_{1}=\mathrm{H}, \mathrm{CH}_{3}, \mathrm{CF}_{3}, i-\mathrm{Pr}, n-\mathrm{Bu}$, sec-Bu, $i$-Bu, $n$-Hex, $\mathrm{Ar}$

$\mathrm{R}_{2}=\mathrm{H}, \mathrm{CH}_{3}$

$\mathrm{R}_{3}=\mathrm{H}, \mathrm{CH}_{3}, n$-Hex, CCPh, Ar $\mathrm{R}_{4}=\mathrm{H}, \mathrm{CH}_{3}$

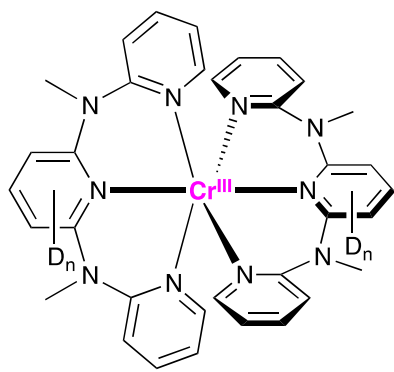

${ }^{2} \mathrm{MLCT} \tau$ up to $2.3 \mathrm{~ms}$ $D_{n}=D_{6}, D_{9}, D_{14}$

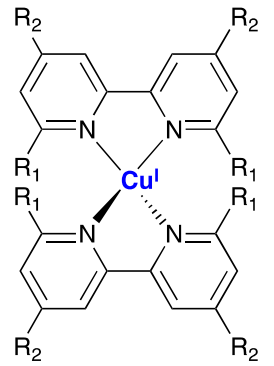

$\mathrm{R}_{1}=\mathrm{H}, \mathrm{CH}_{3}, \mathrm{Ar}$ $\mathrm{R}_{2}=\mathrm{H}, \mathrm{CH}_{3}, \mathrm{C}(\mathrm{O}) \mathrm{OCH}_{3}$, $\mathrm{C}_{2} \mathrm{H}_{2} \mathrm{R}^{\prime}, \mathrm{Ar}$
Since the pioneering studies on water splitting with $\mathrm{TiO}_{2},{ }^{14}$ there has been impressive progress on using semiconductors as chromophores in AP system with work on nanostructuring and doping among the many popular routes. However, more comprehensive reviews about semiconductor photosensitizers and photocatalysts for AP have been discussed in greater detail elsewhere. ${ }^{18-20}$ Furthermore, porphyrin- and porphyrinoid-type sensitizers and their applications in AP have been exhaustively reviewed and will not be discussed in this article. ${ }^{8,21-24}$ Instead, in the next few sections, we will focus on molecular chromophores

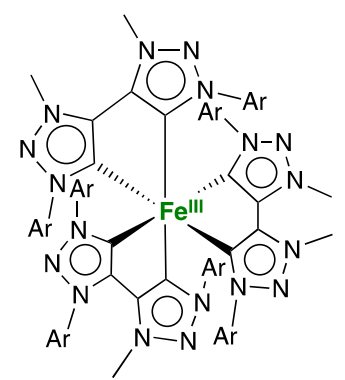

${ }^{2}$ MLCT $\tau$ up to 100 ps Ar $=p$-tolyl

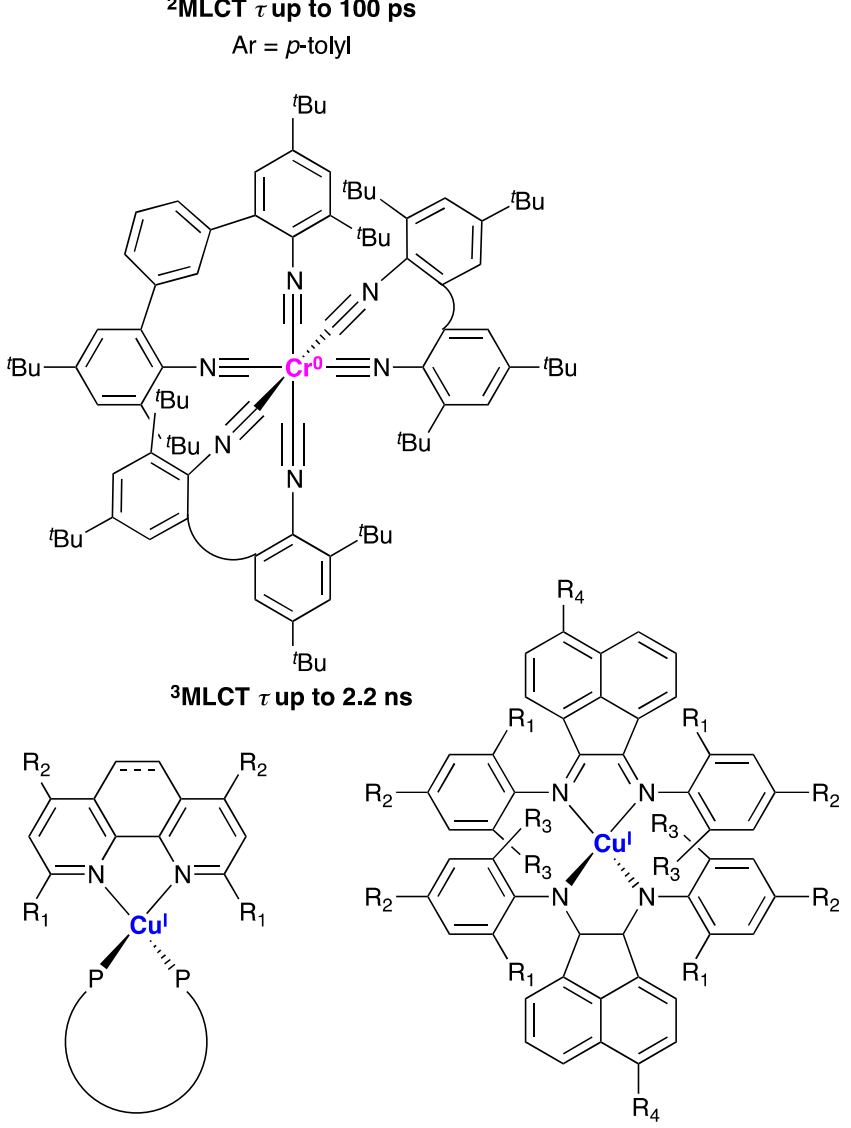

${ }^{3} \mathrm{MLCT} \tau$ up to $54 \mu \mathrm{s}$

$\mathrm{R}_{1}=\mathrm{H}, \mathrm{CH}_{3}, \mathrm{CF}_{3}, i-\mathrm{Pr}, n-\mathrm{Bu}$, sec-Bu, $i$-Bu, $n$-Hex, Ar

$\mathrm{R}_{2}=\mathrm{H}, \mathrm{CH}_{3}, n-\mathrm{Hex}, \mathrm{CCAr}, \mathrm{Ar}$ Bidentate phosphine $=$ DPEphos xantphos, thixantphos
3IL $\tau$ up to 40 ps

$\mathrm{R}_{1}=\mathrm{H}, \mathrm{CH}_{3}, i-\mathrm{Pr}, \mathrm{Ar}$, I $\mathrm{R}_{2}=\mathrm{H}, \mathrm{CH}_{3}, \mathrm{OR}^{\prime}, \mathrm{N}\left(\mathrm{CH}_{3}\right)_{2}, \mathrm{Cl}$, $\mathrm{C}(\mathrm{O}) \mathrm{OCH}_{3}, \mathrm{SO}_{3}{ }^{-}, \mathrm{NO}_{2}$

$\mathrm{R}_{3}=\mathrm{H}, \mathrm{CH}_{3}, i-\mathrm{Pr}$ $\mathrm{R}_{4}=\mathrm{H}, \mathrm{C}(\mathrm{O}) \mathrm{OCH}_{3}, \mathrm{COOH}$

Fig. 2 Several classes of complexes comprising first-row transition metals such as $\mathrm{Fe}, \mathrm{Cr}$, and $\mathrm{Cu}$ recognized as photosensitizers. The lifetimes of the longest-lived variant to date in each class are highlighted. The structures and lifetimes have been summarized from references $31,33-49,53-57$, and $59-64$. 
that can be employed in AP systems. In particular, we consider the most recently developed charge transfer-based complexes containing the relatively more abundant first row transition metals (Fig. 2), but also the unusual class of all inorganic, metal-to-metal charge transfer (MMCT) units as photosensitizers in AP.

\subsection{Molecular light absorbers comprising earth-abundant first-row transition metals}

The platinum group metal complexes have traditionally been the workhorse among photosensitizers used in AP, with the most widely used being ruthenium ( $\mathrm{Ru}$ ) polypyridyl complexes. ${ }^{25-27}$ Since $\mathrm{Ru}$ is a second-row transition metal with a stronger ligand field than the first-row elements, the Ru polypyridyl complexes typically exhibit a number of desirable properties for AP. This includes longlived photoexcited states, high chemical stability due to the stronger metal-ligand bonds (and consequently reversible electrochemistry), and visible light absorption, to name a few. ${ }^{28}$ Despite the long history of Ru photosensitizers, the groups of Hammarström and Berlinguette have only recently demonstrated that judicious ligand design to install a more idealized octahedral environment, coupled with the introduction of strong-field carbene ligands, can dramatically increase the excited state lifetime. ${ }^{29}, 30$ Nonetheless, there has been perennial interest in replacing platinum group metal complexes with more earth-abundant firstrow transition metal counterparts such as iron (Fe), chromium ( $\mathrm{Cr}$ ), and copper $(\mathrm{Cu})^{28}$ with few non-porphyrinoid examples of the other elements due to their shortlived excited states.

In accord with expected periodic trends, there have been numerous attempts to prepare analogous octahedral Fe polypyridyl photosensitizers. However, although many Ru photosensitizers with triplet metal-to-ligand charge transfer ( $\left.{ }^{3} \mathrm{MLCT}\right)$ excited state lifetimes of at least 100 nanoseconds (ns) are known, there are currently still no instances of $\mathrm{Fe}$ complexes with photoexcited lifetimes above 100 picoseconds (ps). ${ }^{31}$ McCusker and coworkers proposed that a number of higher energy ligand-field states mediate the non-radiative relaxation of the ${ }^{1} \mathrm{MLCT}$ excited state to the ${ }^{5} \mathrm{~T}_{2}$ excited state within less than 300 femtoseconds (fs) among most Fe photosensitizer candidates. ${ }^{32}$ Subsequently, the relaxation from the ${ }^{5} \mathrm{~T}_{2}$ back to the singlet ${ }^{1} \mathrm{~A}_{1}$ ground state is also facile and non-radiative, highlighting how spin selection rules do not appear to inhibit the excited state intersystem crossing among transition metal complexes. ${ }^{32}$

Progress has been made in moving beyond the paradigm of ${ }^{3} \mathrm{MLCT}$ excited states accessed from low-spin $\mathrm{d}^{6} \mathrm{Fe}^{\text {ll }}$ complexes, directly analogous to the Ru congeners. Damrauer, Shores, and their coworkers adopted an alternative approach by introducing steric strain to prepare high-spin ${ }^{5} \mathrm{~T}_{2}$ ground-state $\mathrm{Fe}^{l l}$ bis(terpyridine) complexes (Fig. 2). ${ }^{33}$, 34 Remarkably, the photoexcited ${ }^{7} \mathrm{MLCT}$ exhibits a lifetime of up to $17.4 \mathrm{ps}$, which is two orders of magnitude longer than the ${ }^{3} \mathrm{MLCT}$ in the generic lowspin $\left[\mathrm{Fe}(\mathrm{bpy})_{3}\right]^{2+}$ (bpy $=2,2^{\prime}$-bipyridine) complex. ${ }^{33},{ }^{34}$ Although the short lifetimes preclude their use even in diffusion-controlled ( 0.1 ns) intermolecular charge transfer reactions, Fe photosensitizers can still be productively employed in AP provided that the charge extraction rates exceed the non-radiative vibrational or recombination processes. For instance, Wärnmark and his team have provided a roadmap for how novel $N$-heterocyclic carbenes (NHCs), such as those used in Berlinguette's Ru complexes, can be used to increase the photoexcited, doublet ligand-to-metal charge transfer ( $\left.{ }^{2} \mathrm{LMCT}\right)$ lifetime to around $100 \mathrm{ps}$ at room temperature (Fig. 2). ${ }^{31}$ Moreover, they had previously shown that a NHC Fe complex could inject electrons into the conduction band of $\mathrm{TiO}_{2}$ in a dye-sensitized solar cell (DSSC) within $\sim 3$ ps with quantum yields of up to $92 \% .{ }^{35}$ Clearly, there are still promising avenues to explore by using ligand design and ingenuity to prolong the MLCT or LMCT lifetimes of Fe-based photosensitizers for AP applications.

Besides $\mathrm{Fe}$ among the first-row transition metal series, octahedral $\mathrm{Cr}$ complexes have also been investigated in photochemical applications, ${ }^{32}$ presumably due to the established long-lived emissive properties in ruby lasers. $A{ }^{4} T_{2}$ ground-state $\left[\mathrm{Cr}\left(\mathrm{Ph}_{2} \text { phen }\right)_{3}\right]^{3+}\left(\mathrm{Ph}_{2}\right.$ phen $=$ bathophenanthroline $)$ complex with a 13 microsecond ( $\mu \mathrm{s}$ ) ${ }^{2} \mathrm{E}$ excited state was reported to oxidize anethole to a radical cation during a photoredox Diels-Alder cycloaddition reaction (Fig. 2). ${ }^{36}$ Even though the $\mathrm{Cr}^{\text {III }}$ complexes already possess synthetically practical $\mu$ s lifetimes, Heinze and coworkers have employed ligand deuteration to shut down $\mathrm{C}-\mathrm{H}$ vibrational overtone relaxation processes and prolong the lifetime of luminescent $\mathrm{Cr}^{\text {III }}$ polypyridine complexes up to a record of 2.3 milliseconds (ms) $!^{37}$ Another novel approach to use octahedral $\mathrm{Cr}$ complexes is the recognition that $\mathrm{Cr}^{0}$ is isoelectronic with $\mathrm{Fe}^{\prime \prime}$, opening up the possibility of accessing $\mathrm{Cr}^{0}$ photosensitizers. Wenger and coworkers developed bidentate, chelating diisocyanide ligands and accessed powerful $\mathrm{Cr}^{0}$ photoreductants with excited state redox potentials of $-2.43 \mathrm{~V}$ vs $\mathrm{Fc}^{+} / \mathrm{Fc}$ and lifetimes of $2.2 \mathrm{~ns}$ (Fig. 2). ${ }^{38}$ These developments mark only the tip of the iceberg in the potential application of new first-row transition metal complexes for AP.

In addition to $\mathrm{Fe}$ and $\mathrm{Cr}$, the most extensively studied first-row transition metal photosensitizers are $\mathrm{Cu}^{\prime}$ compounds. Similar to the aforementioned photosensitizers, the $\mathrm{Cu}^{\prime}$ complexes absorb light through MLCT processes and are consequently also supported by diimine ligands such as bipyridines and phenanthrolines (Fig. 2). Several other properties suggest that $\mathrm{Cu}^{\prime}$ photosensitizers can be viable competitors against the dominance of platinum group variants, including the following.

(i) The smaller ligand fields facilitate tuning of the absorption and emission behavior in the visible region through systematic ligand functionalization and substitution. The donor properties, size, and substitution pattern will alter both the ground- and excited-state characteristics, allowing for panchromatic absorption to maximize utilization of the solar spectrum. $28,39,40$

(ii) The excited state redox potentials remain synthetically useful with suitable choice of ligands. In fact, the $\left[\mathrm{Cu}(\mathrm{dpp})_{2}\right]^{+}$ complex (dpp = 2,9-diphenyl-1,10-phenanthroline) is a stronger photoreductant than the archetypal $[\mathrm{Ru}(\mathrm{bpy})]^{2+}$, indicating that $\mathrm{Cu}^{\prime}$ photosensitizers possess similarly versatile photoredox chemistry. ${ }^{28,40}$ 
(iii) The ${ }^{3} \mathrm{MLCT}$ excited states are sufficiently long-lived with similar ranges, in the same order of magnitude as the best Ru complexes. ${ }^{28,40,41}$

(iv) $\mathrm{Cu}$ is more earth-abundant and cheaper, making it an economically attractive replacement for platinum group metals. ${ }^{28,39}$

Despite all these benefits, $\mathrm{Cu}^{\prime}$ complexes suffer from some undesirable problems. Chief among them is the kinetic lability of the complexes due to the weaker metal-ligand bonds, which compromises their stability especially in coordinating solvents. Perhaps more critically, the excited state structural dynamics is distinct from the established octahedral $\mathrm{Ru}$ systems since $\mathrm{Cu}^{\prime}$ complexes typically have coordinatively unsaturated tetrahedral or pseudo-tetrahedral geometries. The generally accepted model for these four-coordinate $\mathrm{d}^{10}$ complexes is that after light absorption, the Franck-Condon MLCT state has a propensity to undergo a pseudo-Jahn-Teller flattening distortion due to the unequal occupancy of the almost degenerate d-orbitals (Fig. 3a).28, 39, 41, 42 Chen et al. combined fs optical transient absorption spectroscopy (TAS) with ps synchrotron-based X-ray pulses to elucidate the excited state structural evolution and confirmed that $\left[\mathrm{Cu}(\mathrm{dmp})_{2}\right]^{+}$ ( $\mathrm{dmp}=$ 2,9-dimethyl-1,10-phenanthroline) indeed undergoes this flattening distortion. ${ }^{41}$ Within $500 \mathrm{fs}$, the initial MLCT state undergoes intersystem crossing to the flattened triplet, after which a five-coordinate exciplex can form under diffusion control (Fig. 3). $\mathrm{X}$-ray absorption measurements indicate that a strong interaction with solvent molecules or counterions will quench the luminescence and dramatically shorten the excited state lifetime. ${ }^{41}$ These fundamental insights have paved the way for the development of $\mathrm{Cu}$ photosensitizers with longer-lived excited states and greater structural stability.

Having identified that a main factor for the debilitating nonradiative relaxation of the ${ }^{3} \mathrm{MLCT}$ excited states of $\mathrm{Cu}^{\prime}$ is the flattening distortion and exciplex formation, one approach is to introduce steric bulk to shield the metal center from coordinating ligands. In this regard, sec-butyl, isopropyl, and aryl groups have been introduced to the 2,9-positions of 1,10-phenanthroline to inhibit the exposure of the excited state $\mathrm{Cu}^{1 *}$ center to coordinating ligands (Fig. 2). ${ }^{39,}$ 40, 43-49 Furthermore, through the use of poorly coordinating solvents such as dichloromethane, remarkably longlifetimes of $2.80 \mu$ s with a photoluminescence quantum yield of $6.3 \%$ could be achieved for $\left[\mathrm{Cu}(\mathrm{dsbtmp})_{2}\right]^{+}(\mathrm{dsbtmp}=2,9-\mathrm{di}(\mathrm{sec}-$ butyl)-3,4,7,8-tetramethyl-1,10-phenanthroline)..$^{40,43}$ Consequently, these long-lived $\mathrm{Cu}^{\prime}$ photosensitizers have now been directed towards productive photoredox carbon-carbon bond formation catalysis, ${ }^{49}$ photochemical upconversion for solar cells, ${ }^{48}$ and the production of solar fuels including $\mathrm{H}_{2} .{ }^{46}$

Beyond phenanthrolines and bipyridines, other commercially available or synthetically more accessible ligands have recently received greater attention. Bidentate phosphines including bis[(2diphenylphosphino)phenyl]-ether (DPEphos) and 4,5Bis(diphenylphosphino)-9,9-dimethylxanthene (xantphos), chiral phosphines, and carbazoles have been used, sometimes simultaneously with phenanthroline ligands, to modulate the electronic structure and sterics of the $\mathrm{Cu}^{\prime}$ complexes (Fig. 2). ${ }^{47,} 50-52$ (a)

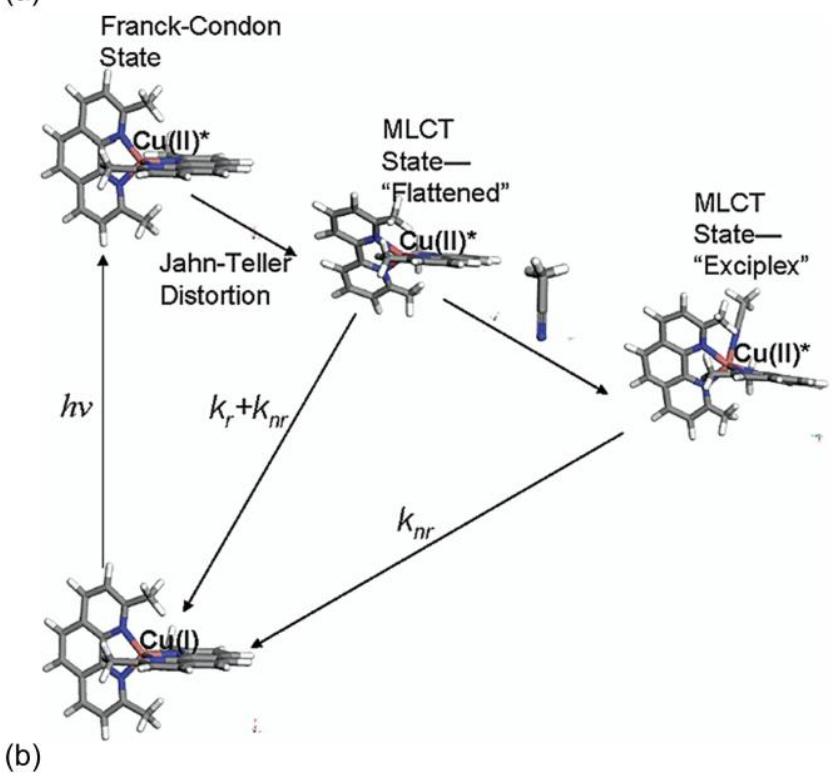

${ }^{1} \mathrm{MLCT}$

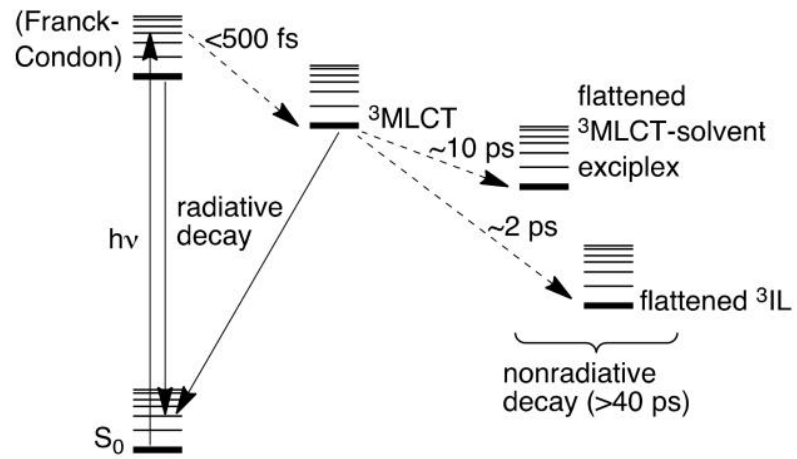

Fig. 3 (a) Typical proposed pathway for the generation and decay of the MLCT photoexcited state of tetrahedral $\mathrm{Cu}^{\prime}$ complexes, with $\left[\mathrm{Cu}(\mathrm{dmp})_{2}\right]^{+}$as a specific example. This figure has been reproduced with permission from Chen et al. Copyright 2003 American Chemical Society. ${ }^{41}$ (b) Simplified Jablonski diagram depicting the excited state processes of $\mathrm{Cu}^{\prime}$ complexes together with exemplary timescales. The lifetimes have been obtained from representative references 41 and 56 .

Phosphines are soft and strong-field ligands able to support $\mathrm{Cu}^{\prime}$ complexes, and are ubiquitous due to their importance for synthetic organic coupling chemistry. Fu, Peters, and their team have demonstrated that $\mathrm{Cu}^{\prime}$ complexes generated in situ can be employed for photoredox inner-sphere carbon-carbon and carbonnitrogen bond formation reactions. ${ }^{50-52}$ A suitable choice of chiral phosphine can facilitate even asymmetric catalysis, ${ }^{51}$ showcasing how $\mathrm{Cu}^{\prime}$ photosensitizers are gradually being adopted in applications dominated by platinum group metal complexes.

In addition, our team and others have sought to incorporate the previous insights on chelating diimine ligands to introduce synthetically facile bis(arylimino)acenaphthene (Ar-BIAN) ligands to support $\mathrm{Cu}^{\prime}$ complexes (Fig. 2). ${ }^{53-56}$ Although $\mathrm{Cu}^{\prime}$ photosensitizers have photochemical performances on par with Ru complexes now, the steric and electronic criteria necessitates expensive and often multi-step functionalization of the commercially available 
bipyridines, phenanthrolines, and phosphines. On the contrary, ArBIAN ligands are highly versatile and stable $\pi$-acceptors able to accommodate up to four electrons, and can be prepared in one step from condensation of a diverse number of cheap, sterically varied anilines with acenaphthenequinone. ${ }^{57,58}$

By prudent selection of ortho-substituted anilines, suitably bulky Ar-BIAN ligands can be prepared to stabilize $\mathrm{Cu}^{\prime}$ complexes against the excited state flattening distortion. Our team installed ortho iodo groups on Ar-BIAN ligands both for steric reasons and also to provide the heavy-atom effect to prolong the excited state lifetime (Fig. 2). ${ }^{53}$ The resultant $\mathrm{Cu}^{\prime}$ complexes exhibited panchromatic light absorption extending to $1400 \mathrm{~nm}$ in the nearinfrared (NIR) region, and were incorporated into DSSCs as a proof of concept. ${ }^{53}$ Subsequently, the ligand and even the metal complex synthesis was improved through the use of essentially solvent-free mechanochemical ball-milling. ${ }^{59,} 60$ However, as Zysman-Colman and Tkachenko have observed previously, the significant spatial overlap between the frontier orbitals in the $\mathrm{Cu}^{\prime}$ complexes have created non-emissive triplet intraligand ( ${ }^{\mathrm{IL}} \mathrm{L}$ ) states that quench the luminescence (Fig. 3b). ${ }^{54-56,61-63}$ The synthetic ease of modifying ArBIAN ligands is a benefit to overcome these problems. Our team is currently working with Zysman-Colman to functionalize the bayregion of Ar-BIAN ligands with electron-deficient groups to serve the dual purposes of localizing the spin density on the acenaphthene motif, and also provide anchoring groups for device applications. ${ }^{64}$ We anticipate that our upcoming $\mathrm{Cu}^{\prime}$ photosensitizers will become appealing, more affordable candidates for light absorption in AP applications in the near future.

\subsection{All-inorganic light absorbers}

Although molecular first-row transition metal complexes have increasingly impressive photochemical characteristics, they still potentially suffer from the oxidative and kinetic instability prevalent among compounds supported by organic ligands. Moreover, retrieval and reuse of the dissolved photosensitizers could pose operational challenges in large-scale artificial photosynthetic systems. To overcome these issues, but still retain the chemical and photophysical selectivity of molecular units, some all-inorganic, discrete single-site chromophores that have been developed include polyoxometalates (POMs) and metal-to-metal charge transfer (MMCT) units (Fig. 4). POMs have been thoroughly reviewed and will not be included in this article, ${ }^{65-67}$ and the following section will largely focus on MMCT units as chromophores (a)

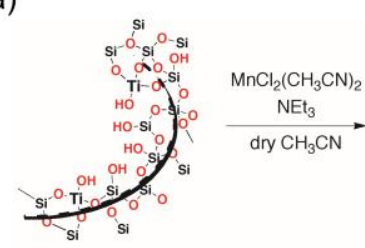

(d)
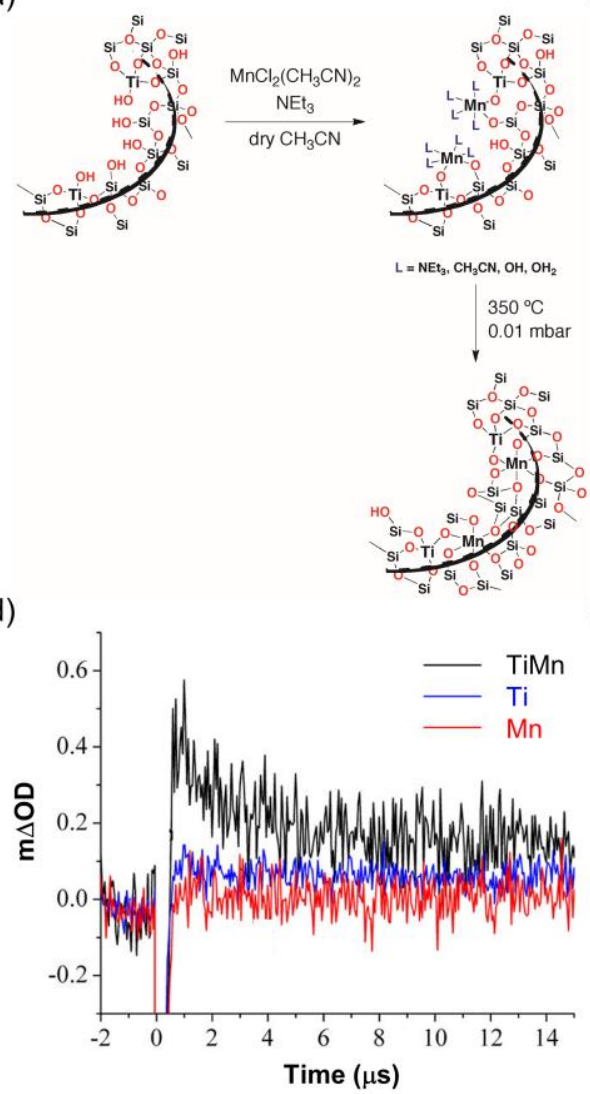
$350^{\circ} \mathrm{C}$ $0.01 \mathrm{mbar}$ Si Tílo omn-si-

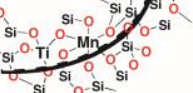

(b)

$L=\mathrm{NE}_{3}, \mathrm{CH}_{2} \mathrm{CN} \mathrm{OH}_{1} \mathrm{OH}_{2}$

(e)
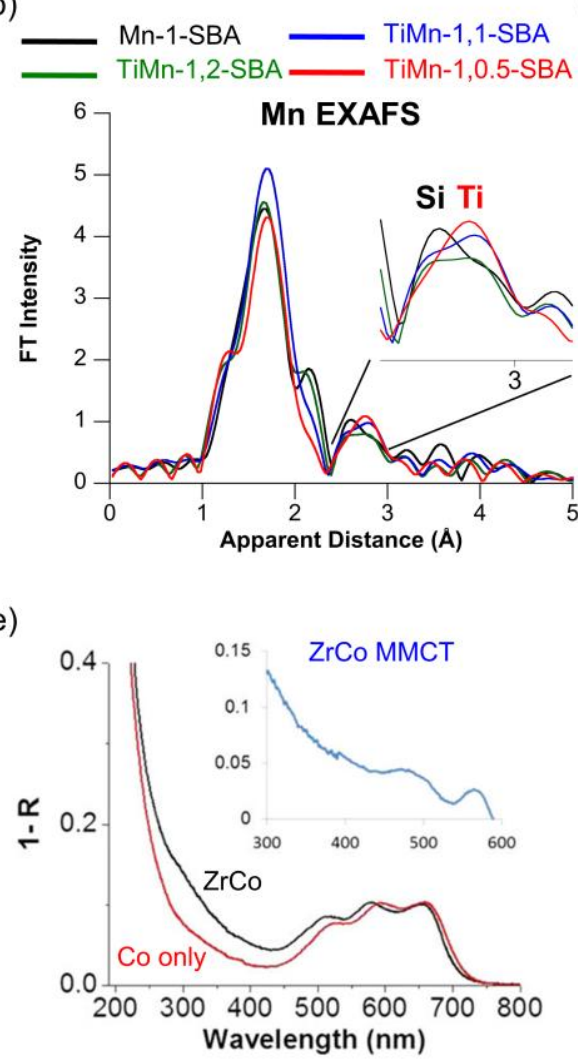

(f)

(c)
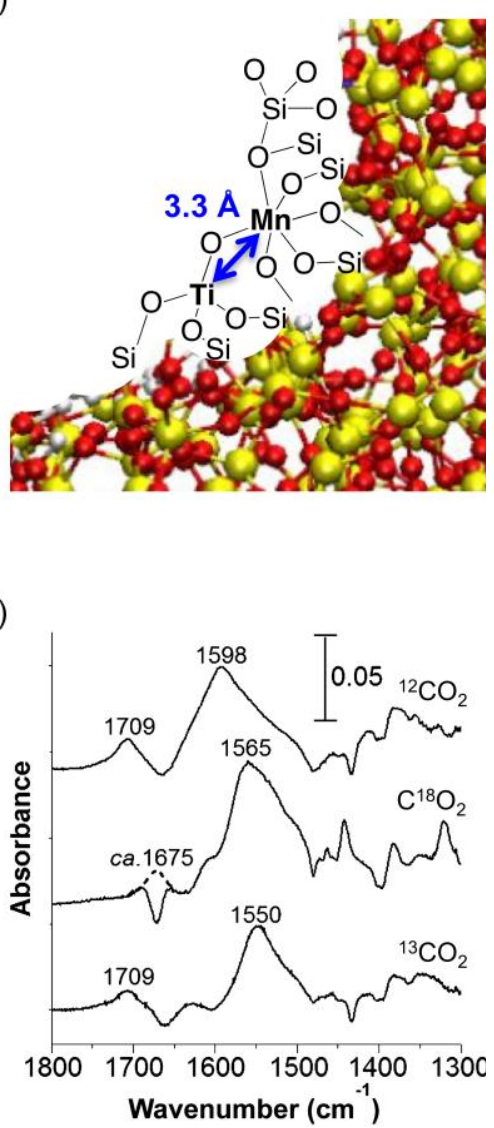

Fig. 4 (a) Representative synthetic route, (b) Fourier transform of Mn K-edge EXAFS data (with an expanded region in the inset), (c) structural model, and (d) transient absorption spectroscopic data pumped at $420 \mathrm{~nm}$ and probed at $580 \mathrm{~nm}$ of TivOMn" MMCT units. These figures are adapted with permission from McClure et al. Copyright 2014 American Chemical Society. ${ }^{69,82}$ (e) UV-visible diffuse reflectance spectra (DRS) of Co"l only and Zr'vOCo" MMCTs embedded in SBA-15. The inset is the difference spectrum between Zr'vOCo"l and $\mathrm{Co}^{\prime \prime}$, which corresponds to the MMCT absorption. (f) FT-IR difference spectra of the isotope labeling studies with ${ }^{12} \mathrm{CO}_{2}, \mathrm{C}^{18} \mathrm{O}_{2}$, and ${ }^{13} \mathrm{CO}_{2}$ showing the isotope shift from 1598 to $1550 \mathrm{~cm}^{-1}$ due to formate $\left(\mathrm{HCO}_{2}^{-}\right)$production. The figures are adapted from reference 68. 
and photosensitizers.

One of our team has previously worked on a unique class of heterogeneous and yet are bona fide molecular photosensitizers in the form of MMCT units. ${ }^{68,} 69$ MMCT units are all inorganic, heterobinuclear chromophores bridged by a $\mu$-oxo between two transition metals. ${ }^{70-72}$ These thermally robust units are embedded on the surfaces of mesoporous silica, but can conceivably be installed on any stable metal oxide with suitable precursors. They typically consist of an electron acceptor like $\mathrm{d}^{0} \mathrm{Ti}^{\mathrm{IV}}$ or $\mathrm{Zr}^{\mathrm{IV}}$, coupled with an electron donor including $\mathrm{Cr}^{\prime \prime \prime}, \mathrm{Mn}^{\prime \prime}, \mathrm{Fe}^{\prime \prime}, \mathrm{Co}^{\prime \prime}, \mathrm{Cu}^{\prime}$, and $\mathrm{Ce}^{\mathrm{III}}$.68, 69, 71-83 By astutely selecting the electron acceptor and donor, the redox potentials of the electron donor and acceptor can be tailored towards AP, with absorption onsets from the UV to visible regions. More comprehensive reviews have been published and only a cursory discussion about the synthesis, characterization, and reactivity studies with select $\mathrm{MMCT}$ units will be elaborated in this article to highlight their apt features for AP.

The preparation procedure involves grafting the two metals sequentially and taking advantage of the more acidic $\mathrm{Ti}-\mathrm{OH}$ or $\mathrm{Zr}-\mathrm{OH}$ over silica $\mathrm{Si}-\mathrm{OH}$ protons to selectively assemble the MMCT units (Fig. 4a). Titanocene and zirconocene complexes have been cheap, common, and convenient precursors to graft on the silica at less than 2 mol\% of transition metal to silicon to ensure isolated units. ${ }^{69}$, 74-76, 79-81, 83 The organic ligands are then removed by calcination, after which a halide complex of the electron donor (e.g. $\mathrm{MnCl}_{2}\left(\mathrm{CH}_{3} \mathrm{CN}\right)_{2}$ ) can be selectively deposited adjacent to the electron acceptor by using no base or a weak organic base such as triethylamine (Fig. 4a). ${ }^{74}, 83$ The remaining solvents or non-oxo ligands can then be removed by annealing in vacuo at moderate temperatures up to $350{ }^{\circ} \mathrm{C} .{ }^{74,83}$ The elemental ratios can then be verified by ICP-MS measurements, with the relative compositions of electron donor and acceptor usually below a factor of $2.74,83$

The MMCT units characteristically have broad absorption profiles from the UV and extend into the visible region, due to the heterogeneity and distribution of the MMCT sites on the surface of silica (Fig. 4e). ${ }^{68,71-76,79-81,83}$ The absorption band attributable to the MMCT motif only can be estimated by subtracting the normalized contributions from just a superposition of the LMCT bands of the electron acceptor and the $d$ - $d$ transitions from the electron donor. ${ }^{68,71-76,79-81,83}$ The panchromatic absorption allows effective harvesting of the solar spectrum. The oxidation states of the constituent metal centers were determined by X-ray absorption near edge structure (XANES) measurements. ${ }^{74}, 76,80,83$ More crucially, the integrity of the MMCT units could be evaluated by extended X-ray absorption fine structure (EXAFS), which provided the metal-metal bond distances and the bond angles of the

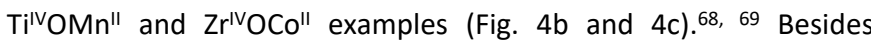
steady-state spectroscopic characterization, the excited state lifetime had been measured by ns TAS and remarkably long lifetimes of up to $2.4 \mu$ s for the TivOMn" were observed (Fig. 4d). ${ }^{73}$, 82

With the long-lived excited states in some of these MMCT units, they have been successfully applied in photoredox catalytic reactions. ${ }^{77}$ Nakamura et al. have exploited a TilvOCe ${ }^{\text {III }}$ MMCT to harvest light for the oxidation of isopropanol to acetone and $\mathrm{CO}_{2}$ with $\mathrm{O}_{2}{ }^{84}$ whereas a TivOMn" MMCT could oxidize methanol to methyl formate. ${ }^{83}$ In a series of studies, the Frei group has demonstrated the application of these MMCT units for water oxidation and $\mathrm{CO}_{2}$ reduction catalysis. A $\mathrm{Zr}^{\mathrm{IV} O C \mathrm{Cu}^{\prime}}$ chromophore was first shown to reduce $\mathrm{CO}_{2}$ to $\mathrm{CO}$ stoichiometrically with

(a)

(b)
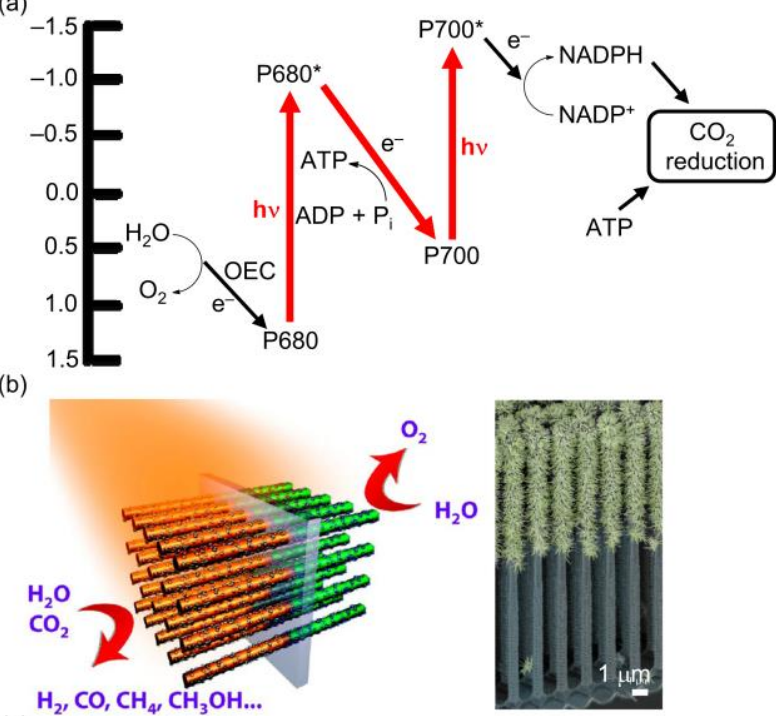

(c)

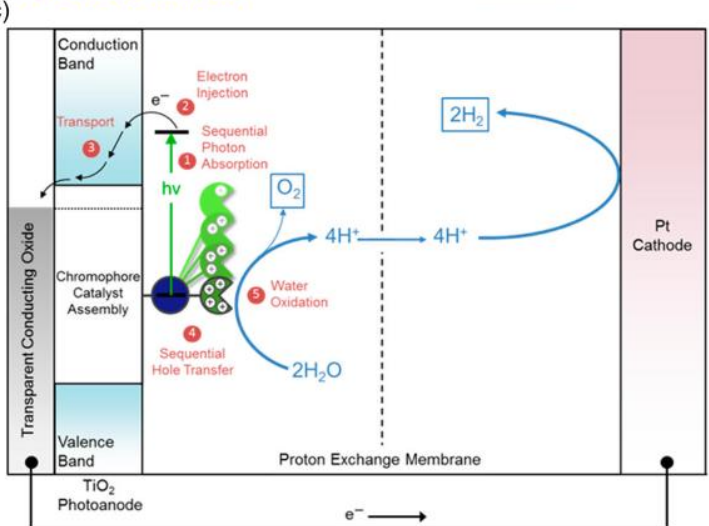

(d)

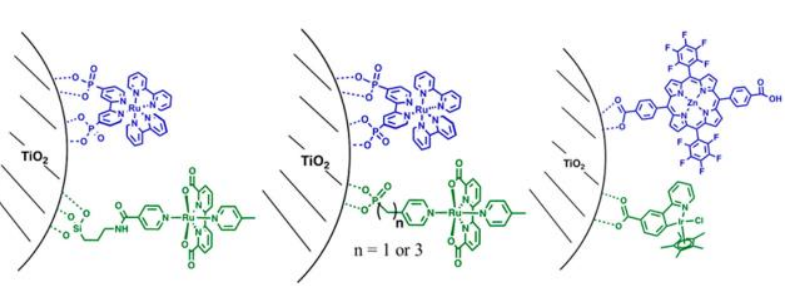

Fig. 5 (a) Simplified Z-scheme highlighting only the essential light absorption, electron flow direction, and multielectron $\mathrm{H}_{2} \mathrm{O}$ oxidation and $\mathrm{CO}_{2}$ reduction aspects. (b) A wireless model of the Z-scheme (left) with simultaneous light absorption by two semiconductors as the photoanode and photocathode. A SEM image of such an actual system composed of $\mathrm{TiO}_{2}$ and $\mathrm{Si}$ is shown on the right, reproduced with permission from Liu et al. Copyright 2014 American Chemical Society. ${ }^{18}$ (c) Model of DSPEC system and (d) common anchoring groups utilized previously including phosphonates, carboxylates, and siloxides. The figures are adapted with permission from Ashford et al. Copyright 2015 American Chemical Society. ${ }^{25}$ 
concomitant oxidation to $\mathrm{Cu}^{\prime \prime}$ in a one-photon, two-electron process (355 nm irradiation). ${ }^{81}$ Subsequently, a ZrivOCo" MMCT could reduce $\mathrm{CO}_{2}$ to $\mathrm{CO}$ and formate, ${ }^{68}$ and the same $\mathrm{MMCT}$ when coupled with $\mathrm{Cu}_{2} \mathrm{O}$ nanocrystals could catalytically reduce $\mathrm{CO}_{2}$ to $\mathrm{CO}$ with amines as the sacrificial electron donor. ${ }^{78}$ For the oxidative half-reaction, $\mathrm{IrO}_{x}$ nanoparticles were loaded by impregnating mesoporous silica containing $\mathrm{Ti}^{\mathrm{IV} O \mathrm{OC}} \mathrm{rll}^{\mathrm{II}}$ sites with $\operatorname{Ir}(\mathrm{acac})_{3}$ followed by mild calcination..$^{75} \mathrm{On}$ irradiating these composites with $460 \mathrm{~nm}$ laser light in a buffered aqueous solution with persulfate as the acceptor, $\mathrm{O}_{2}$ evolution with a $13 \%$ quantum efficiency was observed. ${ }^{75}$ Using the combined insights from these studies, a visible-light driven catalytic cycle for simultaneous water oxidation and $\mathrm{CO}_{2}$ reduction to $\mathrm{CO}$ was achieved with a $\mathrm{Zr}^{\mathrm{IV} O C \mathrm{O}^{\prime \prime}} \mathrm{MMCT}$ connected to $\mathrm{IrO}_{\mathrm{x}}$ nanoclusters. ${ }^{79}$ Isotope labelling studies confirmed the origin of the $\mathrm{CO}$ was from $\mathrm{CO}_{2}$ and $\mathrm{O}_{2}$ was from $\mathrm{H}_{2} \mathrm{O}$ (Fig. 4f). ${ }^{79}$ These instances underscore how the inorganic, robust MMCT units can fulfil many of the criteria as the one-electron photosensitizers for powering multi-electron catalysis in integrated AP systems when suitably selected co-catalysts are present.

\section{Interfacial chemistry and charge separation}

In his early exposition on creating AP systems, Calvin proposed a "Zscheme" in a vesicle, where light absorption and charge separation could take place across a phospholipid membrane (Fig. 5a). ${ }^{7} \mathrm{His}$ prescience derived from insights of the fundamental workings of natural photosynthesis now motivate several approaches to independently optimize the charge separation and catalysis across a physical barrier to separate the products. In biological photosynthesis, the chlorophyll P680 absorbs light as the photosensitizer and initiates a cascade of energetically downhill and kinetically favorable electron transfers through mediating small molecules across a biological membrane to Photosystem I (PS I). 3, 4, 9 On the oxidation side, a tyrosine is oxidized via PCET to a tyrosine radical, which in turn injects holes into the OEC (Fig. 5a). 3, 4, 9 Through such a mechanism, Nature is able to absorb single photons, separate the charges over long distances, and drive $\mathrm{O}_{2}$ evolution and solar fuels production across a lipid membrane. This understanding has led to technologies that parallel this kinetically driven interfacial charge separation process such as DSSCs and more lately, dye-sensitized photoelectrosynthesis cells (Fig. 5). ${ }^{25,85 \text {, }}$ 86 Notably, however, majority of the semiconductor-molecule interfacial systems involve chemisorption through charged functional groups such as carboxylate, phosphonate, catecholate, hydroxamate, thiols, and thiocarbamate (Fig. 5d). ${ }^{25,} 85-89$ Although these anchoring motifs are very prevalent, they are notorious for their hydrolytic instability and limited applicability to metal oxide surfaces, in addition to being already extensively reviewed. 88,89 Here, we examine some of the recent covalent deposition approaches that apply to other material surfaces.

\subsection{Interfacial anchoring groups for non-oxide materials}

Other than metal oxides, there is increasing interest in grafting molecules to other materials such as silicon, gallium phosphide $(\mathrm{GaP})$, carbon nanotubes, graphene, or graphite electrodes. Recently, Yano, Sharp, Moore, and their colleagues reported a robust protocol to graft and polymerize ligands on $\mathrm{p}$-type GaP and nanostructured indium tin oxide (ITO). ${ }^{90-95}$ In their earlier work, the GaP was first hydroxylated by etching with buffered hydrofluoric acid, after which 4-vinylpyridine was anchored by UV irradiation and subsequently photopolymerized (Fig. 6a). ${ }^{93,} 95$ This procedure essentially results in polyvinylpyridine chains covalently bound via alkoxide termination to the GaP surface. Successful grafting was confirmed by a suite of methods including grazing angle attenuated total reflection Fourier transform infrared spectroscopy, X-ray photoelectron spectroscopy (XPS), and XANES (Fig. 6). ${ }^{93,95}$ There are several versatile features about this concept.

(i) The polyvinylpyridine chains are suitable ligands to axially coordinate complexes such as the renowned cobaloxime $\mathrm{H}_{2}$ evolution catalysts. The Co-modified material then becomes an effective photocathode for the photoelectrochemical (PEC) production of $\mathrm{H}_{2}$ in neutral aqueous conditions (Fig. 6a. ${ }^{93}, 95$ Moreover, the multiple pyridine groups promotes self-regeneration even when the cobaloxime is detached (a)

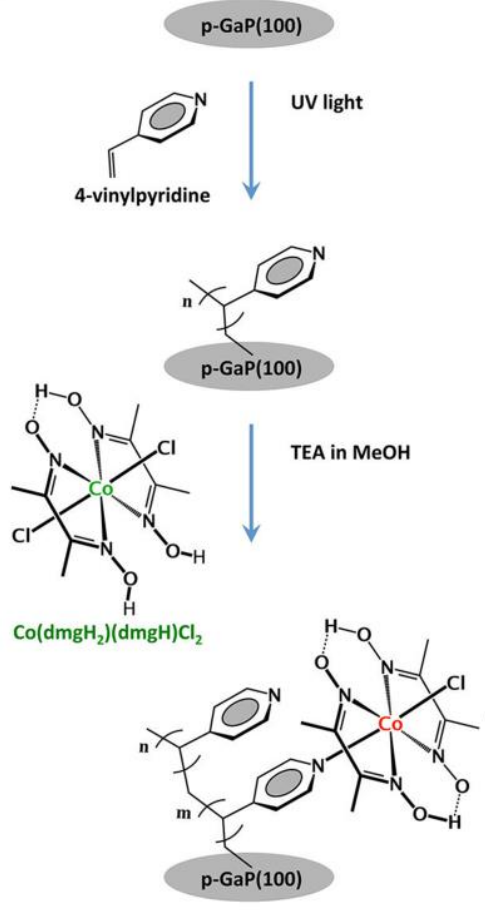

(b)

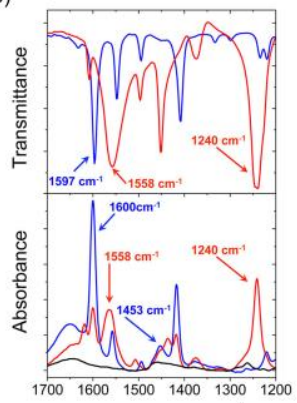

(c)

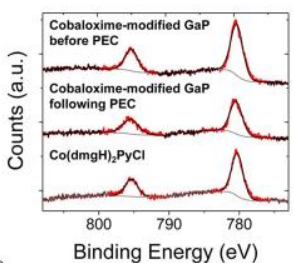

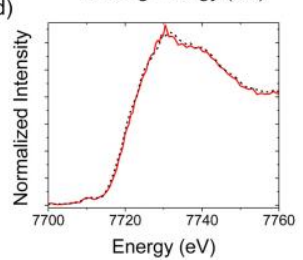

Fig. 6 Reaction scheme for anchoring pyridine ligands and subsequently, cobaloxime complexes on GaP by conversion of terminal alkenes to covalently bound polymer chains. (b) FT-IR spectra illustrating the successful attachment of cobaloxime on GaP with diagnostic peaks at 1240 and $1558 \mathrm{~cm}^{-1}$ from the complex. (c) XPS data of the Co $2 p$ binding energies showing that the cobaloxime remains intact after grafting before and after $\mathrm{H}_{2}$ evolution experiments in a PEC geometry. (d) Co K-edge XANES confirming that the Co coordination sphere remains unmodified before and after $\mathrm{H}_{2}$ evolution catalysis. All the images have been reproduced with permission from Krawicz et al. Copyright 2013 American Chemical Society. ${ }^{93}$ 
during the catalysis.

(ii) The choice of ligand can be varied conveniently using different commercially available vinyl-substituted ligands. Instead of 4-vinylpyridine, $\mathrm{N}$-vinylimidazole was applied in similar fashion to create polyvinylimidazole chains on GaP that were also effective ligands for cobaloxime. ${ }^{90}$ This new Co-modified GaP material was also suitable for $\mathrm{H}_{2}$ evolution in a PEC architecture. ${ }^{90}$

(iii) Other vinyl-substituted compounds, including metal complexes can be directly deposited. Co and Fe porphyrins with vinyl groups on the periphery were attached to GaP, and the modified semiconductors were in turn employed as the photocathode for $\mathrm{H}_{2}$ generation in buffered water solutions..$^{92}$

(iv) The surface is not limited only to GaP. The same approach was utilized to anchor cobaloxime and polyvinylpyridine to ITO. ${ }^{94}$

Patently, this UV mediated anchoring procedure is widely applicable, at least for the reductive half-reaction in AP.

Another general approach to functionalize materials involves the transformation of ortho-phenylenediamine derivatives to become pyrazines after condensation with ortho-quinone edge sites of carbon electrodes. ${ }^{96}$ Surendranath's team disclosed a general approach to covalently anchor redox active small molecules on the edge planes of graphitic carbon electrodes. ${ }^{96}$ Likewise, the electrode materials were all thoroughly characterized by XPS, XANES, and electrochemistry. ${ }^{96}$ This strategy has been used to effectively create a number of electrocatalysts for $\mathrm{O}_{2}$ reduction in alkaline solutions, ${ }^{97} \mathrm{CO}_{2}$ reduction with Re catalysts in acetonitrile, ${ }^{98}$ and potentially photoredox reactions as well. ${ }^{99}$ Since AP systems involve not only photocatalysis but also encompass electrocatalysis, this simple but robust modification of carbon-based electrodes can provide practical and timely solutions for PECs and other integrated systems.

\subsection{New materials and approaches for directed charge separation}

In order to couple single photon light absorption to multielectron catalysis, the photosynthetic Z-scheme bridges PSII and PSI with a sophisticated system of potentially matched small molecule intermediates so that charge separation is both kinetically and thermodynamically favoured over recombination. The Z-scheme thus behaves as a very effective molecular diode. To mimic these functions, the groups of Gust, Thomas and Ana Moore, Fukuzumi, and Hammarström have created molecular dyads, triads, and more complex units to segregate light absorption and create long-lived charge separated states that perform biomimetic catalytic activities. Carotenoid-porphyrins, carotenoid-porphyrin-fullerene/quinones, ${ }^{3,}$ 8 , 22, 100-102 and donor/acceptor-Ru(bpy) ${ }_{3}$-catalyst molecular constructs $^{103}$ have been synthesized and some show almost unity quantum efficiencies for light absorption and charge separation. Some of these triads exploit the large driving force of recombination in the Marcus inverted region to produce long-lived excited states with almost unity quantum yields, 3,8 while others harness concerted proton and electron transfer to accelerate slower stepwise pathways. ${ }^{100,101}$ Although many of these systems are molecular masterpieces, the synthetic challenges in their construction deter adoption in large-scale AP units. Nonetheless, there has been a growing body of work, which has established that charge interchange between molecules and semiconductors, especially metal oxides, can be several orders of magnitude faster than recombination. ${ }^{22,} 25,85-87,103,104$ Consequently, this has inspired us $^{105-108}$ and others to seek new materials and architectures (Fig. 7) to effect the long-lived charge separation to drive multielectron

(a)

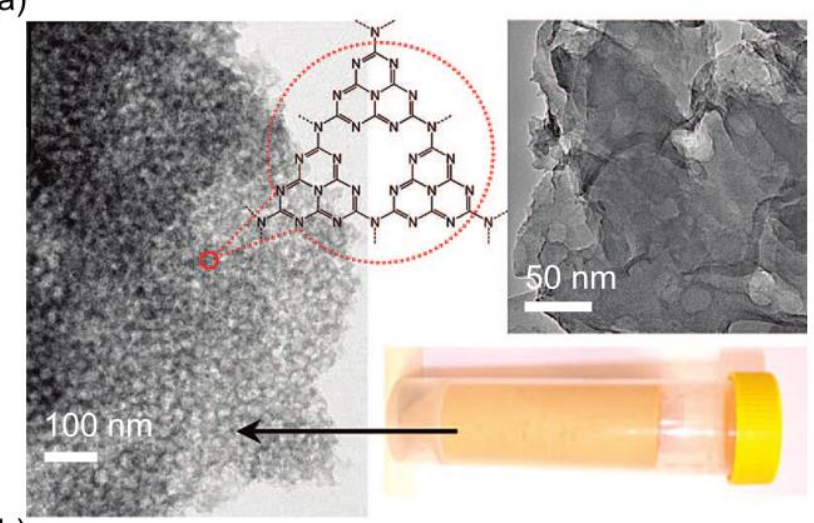

(b)

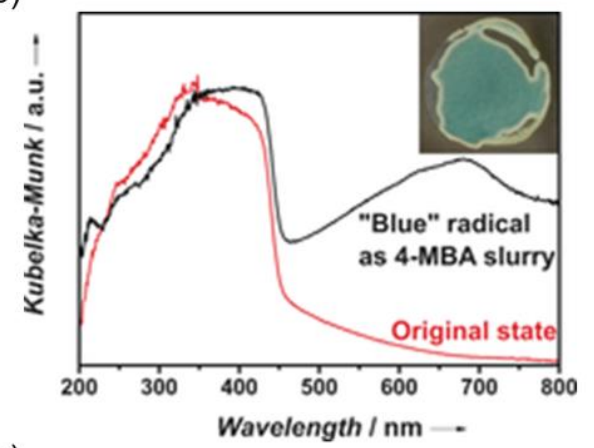

(c)

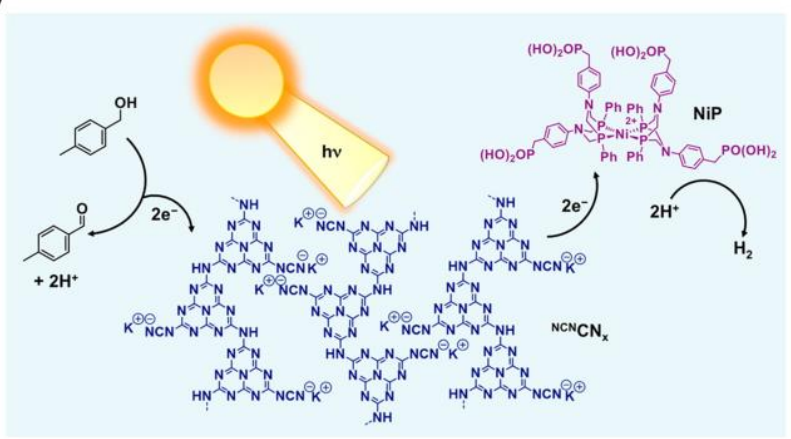

Fig. 7 (a) TEM image of mesoporous $\mathrm{CN}_{\mathrm{x}}$ (left) and bulk $\mathrm{CN}_{\mathrm{x}}$ with a photo illustrating the visible light absorption properties, adapted with permission from Wang et al. Copyright 2009 American Chemical Society. ${ }^{109}$ (b) DRS spectra of cyanamide-functionalized $\mathrm{CN}_{\mathrm{x}}$ that can store electrons after photoreduction, with the blue form shown in the inset. Reproduced with permission from Wiley-VCH Verlag GmbH \& Co. KGaA, Copyright 2016. ${ }^{112}$ (c) $\mathrm{CN}_{x}$ for effective charge separation to couple $\mathrm{H}_{2}$ evolution with a productive alcohol oxidation half-reaction. Reproduced with permission from Kasap et al. Copyright 2016 American Chemical Society. ${ }^{110}$ 
catalysis for AP.

Since the isolation of graphene and other 2D materials, carbonbased semiconductor materials have lately garnered much attention because they are earth-abundant, absorb visible light, and are easily synthesized. In particular, carbon nitride $\left(\mathrm{CN}_{\mathrm{x}}\right)$ has found widespread applications for photocatalysis and AP since the first report on its visible light absorption for $\mathrm{H}_{2}$ evolution, albeit with $\mathrm{Pt}$ as the co-catalyst (Fig. 7a). ${ }^{109}$ Since then, Reisner, Lotsch, and coworkers have increased the rate of $\mathrm{H}_{2}$ evolution and external quantum efficiency by introducing DuBois's exceptional Ni [P2N2] catalysts on $\mathrm{CN}_{\mathrm{x}}{ }^{110}$ as well as carbon quantum dots. ${ }^{111}$ The molecular Ni catalysts appear to extract electrons efficiently despite being only physisorbed to the $\mathrm{CN}_{x} \cdot{ }^{110}$ Most remarkably, the $\mathrm{H}_{2}$ evolution has been coupled with benzylic alcohol oxidation to benzaldehyde (Fig. 7c), which creates a closed redox cycle for both a solar fuel $\left(\mathrm{H}_{2}\right)$ and a solar chemical (benzaldehyde). ${ }^{110}$ This concept of generating two value-added products will be further explored in the following sections on multielectron catalysis.

Another interesting adaptation of $\mathrm{CN}_{x}$ is the use of a cyanamide-functionalized heptazine polymer as a photocapacitor to store solar energy. ${ }^{112}$ The $\mathrm{CN}_{\mathrm{x}}$ was able to capture visible light under an anaerobic environment and turn from yellow to blue in the presence of electron donors (Fig. 7b). ${ }^{112}$ After the irradiation ceased, the $\mathrm{CN}_{\mathrm{x}}$ stored the trapped photoelectrons for up to several hours. Critically, the stored charges could be released in the dark by introducing a co-catalyst such as colloidal $\mathrm{Pt}$, resulting in $\mathrm{H}_{2}$ release. ${ }^{112}$ This work demonstrates a key principle of temporally separating light absorption, charge separation, and catalysis in natural photosynthesis by storing the charges as long-lived radicals in durable and recyclable $\mathrm{CN}_{\mathrm{x}}$ materials.

Likewise, one of our team had previously been involved in the development of a molecular diode to achieve independent light absorption and charge separation across a proton conducting membrane (Fig. 8). In both natural and artificial photosynthesis, (a)

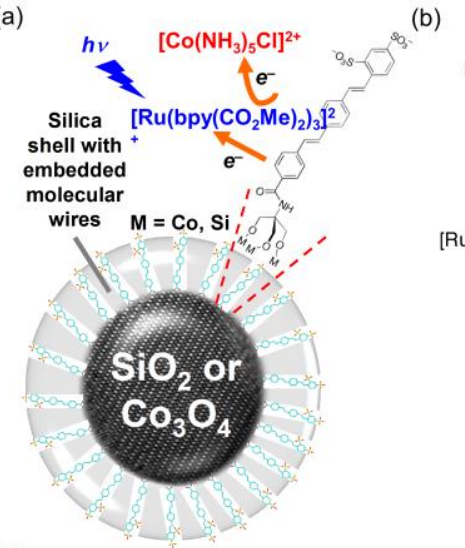

(e)

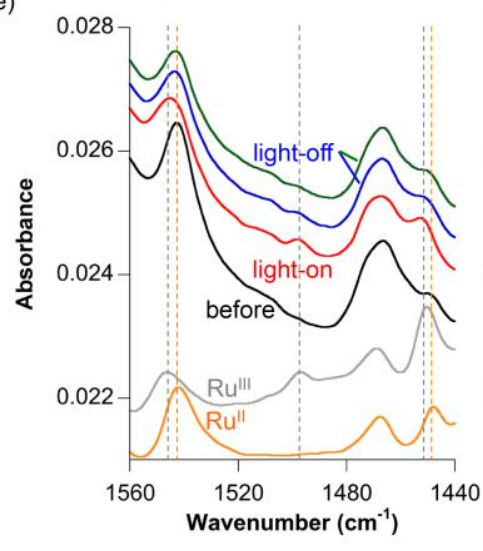

(b)

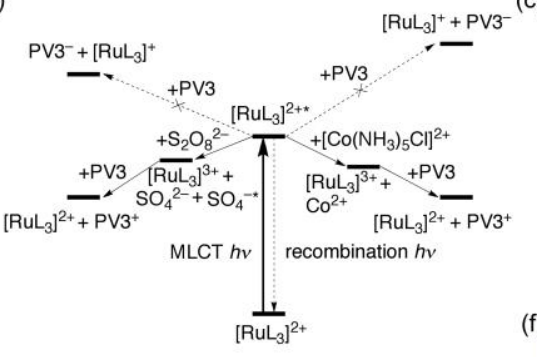

(c)

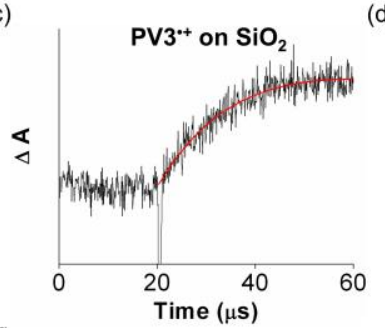

(d)

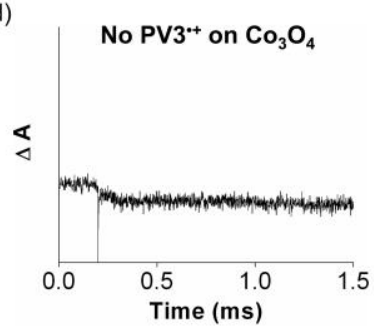

(f)

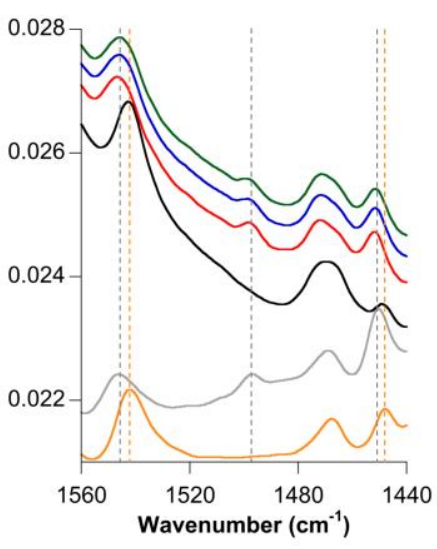

(g)

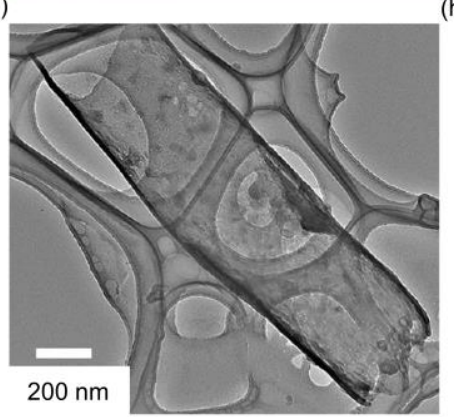

(h)

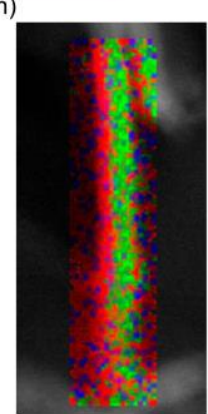

Fig. 8 (a) Schematic of the photosensitization of $\left[\mathrm{Ru}\left(\mathrm{bpy}\left(\mathrm{CO}_{2} \mathrm{Me}\right)_{2}\right)_{3}\right]^{2+}$, oxidative quenching by $\left[\mathrm{Co}\left(\mathrm{NH}_{3}\right)_{5} \mathrm{Cl}\right]^{2+}$, followed by hole injection into $\mathrm{Co}_{3} \mathrm{O}_{4}-\mathrm{SiO}_{2}$ core-shell nanoparticle, mediated by the PV3 molecular wire. (b) Chemical processes leading to hole injection into PV3 after photoexcitation. TAS data after excitation at $450 \mathrm{~nm}$ and probing at $600 \mathrm{~nm}$ illustrating (c) the formation of the $\mathrm{PV}^{+}{ }^{+}$radical cation on the insulating $\mathrm{SiO}_{2}$ control after hole injection by $\mathrm{Ru}^{\prime \prime \prime}$, and (d) the absence of any $\mathrm{PV}^{+}$radical cation on the $\mathrm{Co}_{3} \mathrm{O}_{4}-\mathrm{SiO}_{2}$ core-shell nanoparticle due to subsequent hole injection into $\mathrm{Co}_{3} \mathrm{O}_{4}$ within the instrumental time resolution. These figures are adapted from reference 114. (e) Rapid-scan FT-IR data depicting the hole injection by $\mathrm{Ru}^{\text {III }}$ and recovery of $\mathrm{Ru}^{\prime \prime}$ into the $\mathrm{CO}_{3} \mathrm{O}_{4}-\mathrm{SiO}_{2}$ core-shell nanoparticles with PV3 molecular diodes (left) and the persistence of Ru'll even after $15 \mathrm{~s}$ for particles without PV3 (right). This figure was adapted from reference 117. Model showing the separated $\mathrm{H}_{2} \mathrm{O}$ oxidation and $\mathrm{CO}_{2}$ reduction (f), TEM (g), and EDX elemental map (h) of the $\mathrm{CO}_{3} \mathrm{O}_{4}-\mathrm{SiO}_{2}$ core-shell nanotubes containing embedded PV3 molecular diodes, adapted with permission from Edri et al. ${ }^{118}$ Copyright 2018 American Chemical Society. 
proton gradients build up during $\mathrm{H}_{2}$ evolution or water oxidation. It is thus essential that the reductive and oxidative half-reactions should have proton conducting conduits in between. $\mathrm{Co}_{3} \mathrm{O}_{4}$ is an established and effective water oxidation catalyst, ${ }^{113}$ while silica can be a proton-conducting nanomembranes. To overcome the insulating behavior of silica, we embedded oligo(phenylenevinylene) with three aryl units (PV3) within the silica to function as hole-conducting diodes (Fig. 8a). ${ }^{114}$ PV3 molecules have lowest unoccupied molecular orbital (LUMO) potentials of -1.7 $\checkmark$ relative to the standard hydrogen electrode (SHE), whereas they can be oxidized around $+1.3 \mathrm{~V}$ vs SHE (Fig. $8 \mathrm{~b}$ ). ${ }^{114}$ Therefore, we anchored PV3 molecules on $\mathrm{Co}_{3} \mathrm{O}_{4}$ nanocrystals with a dehydration reaction and formed a thin silica shell around the units to create a core-shell structure (Fig. 8a). ${ }^{114}$ A similar construct with $\mathrm{SiO}_{2}$ nanocrystals as the core was prepared as an insulating control specimen. Through the use of ns TAS and rapid-scan FT-IR experiments, we demonstrated that a long-lived $\mathrm{PV}_{3}{ }^{+}$radical cation could be observed when $\mathrm{Ru}(\mathrm{bpy})_{3}$ derivatives were irradiated and used to inject holes into the silica-only $\mathrm{PV}_{3}$ core-shell constructs (Fig. 8c-e). ${ }^{114,} 115$ On the contrary, since the $\mathrm{PV}_{3}{ }^{+}$radical cation would be thermodynamically favored to inject holes into $\mathrm{CO}_{3} \mathrm{O}_{4}$, the $\mathrm{PV}_{3}$ spectral signature was quenched within the time resolution of the instrument (Fig. 8d), implying that hole injection had taken place within $1 \mu \mathrm{s} .{ }^{114,115}$ Most remarkably, this study was a proof of concept that we were able to absorb visible light and inject charges across an insulating membrane, providing an opportunity for us to separate the products from both the reductive and oxidative halfreactions.

Nonetheless, a spherical core-shell system with the $\mathrm{Co}_{3} \mathrm{O}_{4}$ core is unsuitable as a catalytic system since the water molecules will be unable to access the active sites. Moreover, the thickness of the silica shells in the original solvothermal synthesis processes cannot be precisely controlled. To address these issues, atomic layer deposition (ALD) has been used to create well-defined $\mathrm{Co}_{3} \mathrm{O}_{4}$ thin films coated with thin silica shells with PV3 embedded within. ${ }^{116}$ Electrochemical measurements confirmed that hole injection by $\mathrm{Ru}(\mathrm{bpy}) 3_{3}{ }^{3+}$ was feasible when the PV3 molecular diode has been embedded, and the silica shell was free of pinholes. ${ }^{116}$ Ultrafast TAS experiments on these systems further indicate that chemisorbed porphyrin dyes can inject holes into $\mathrm{PV} 3$ within less than $1 \mathrm{ps}$, while the onward hole transfer to the $\mathrm{Co}_{3} \mathrm{O}_{4}$ occurred in 250 ps. ${ }^{117}$ Recently, silicon ( $\mathrm{Si}$ ) nanorod arrays have been employed as the template for ALD of $\mathrm{CO}_{3} \mathrm{O}_{4}$ and PV3 embedded silica shells, after which the $\mathrm{Si}$ was etched to leave behind arrays of $\mathrm{CO}_{3} \mathrm{O}_{4}$-silica coreshell nanotubes (Fig. 8).118 It is anticipated that these holeconducting molecular diode systems will eventually be integrated as crucial constituents of artificial photosynthetic units with highfidelity unidirectional charge transfer between the multielectron catalytic reductive and oxidative half-reactions, akin to natural photosynthesis.

\section{Multielectron catalysis}

Although light absorption and charge separation are indispensable elements for an AP system, the energy must ultimately be stored in the form of fuels or chemicals. A clean and sustainable fuel and platform chemical is $\mathrm{H}_{2}$, which produces water as a benign product after combustion or in a fuel cell. There are several challenges that hinder widespread adoption of $\mathrm{H}_{2}$ as fuel, including the low volumetric energy density and the source of $\mathrm{H}_{2}$. For the former, there are ongoing efforts to develop new materials to store compressed $\mathrm{H}_{2}$ that will not be covered here. Regarding the latter, majority of the $\mathrm{H}_{2}$ is still generated from fossil fuels, especially by steam reforming of natural gas and coal gasification with the water gas shift reaction. The small remaining fraction is derived from electrolysis of water, but the commercial standard electrode is still predominantly the expensive platinum ( $\mathrm{Pt}$ ). Against this backdrop, there is an urgent need to develop more affordable catalysts for the water reduction reaction so that electrocatalytic or photocatalytic $\mathrm{H}_{2}$ evolution can be price-competitive with $\mathrm{H}_{2}$ from fossil fuels.

With these constraints in mind, there have been many opportunities to discover new materials and molecular catalysts for cost-effective $\mathrm{H}_{2}$ evolution. A number of non-precious metal alloys, chalcogenides, phosphides, nitrides, and carbides, including 2D materials have been found to be efficient proton reduction electrocatalysts with overpotentials similar to $\mathrm{Pt}$ and comparable Tafel slopes. ${ }^{119-121}$ Likewise, there are molecular catalysts composed of only earth-abundant elements that perform with exceptionally high turnover frequencies (TOFs) and turnover numbers (TONs). ${ }^{122,}$ ${ }^{123} \mathrm{~A}$ comprehensive coverage of all these catalysts is beyond the scope of this article. Instead, we will limit the discussion to the following aspects. Foremost, only molecular catalysts comprising earth-abundant elements will be examined. In addition, we will focus mainly on $\mathrm{H}_{2}$ evolution from aqueous or mixed organicaqueous media. If $\mathrm{H}_{2}$ is to be produced practically from photo- or electrocatalysis, the most abundant feedstock is water, especially seawater. Finally, we will showcase subtle aspects of second coordination sphere and other ligand participation effects where our team has contributed in. There are now many functional $\mathrm{H}_{2}$ evolution catalysts and fundamental studies and judicious ligand design will be necessary to tease out further performance improvements in the future.

\subsection{Electrocatalytic reduction for solar fuels and environmental remediation}

In Nature's [FeFe] hydroogenases, the thermodynamics of heterolytic $\mathrm{H}_{2}$ cleavage is poised at almost exactly $0 \mathrm{kcal} \mathrm{mol}^{-1}$ so that they behave as the prototypical Sabatier-type catalysts, where the substrate binds exactly "just right". ${ }^{124}$ One of the features that have been proposed to modulate the [FeFe] hydrogenase's ability to modulate the catalysis so precisely is that the dithiolate ligand bridging the two Fe centers may have an amine to function as a proton shuttle for the enzyme. ${ }^{124}$ This intramolecular base or hydrogen-bonding that is in close proximity to the Fe active site facilitates the heterolytic cleavage of $\mathrm{H}_{2}$ to form a hydride $\mathrm{Fe}-\mathrm{H}$ without a high kinetic barrier. ${ }^{124}$ Conversely, the amine also promotes $\mathrm{H}-\mathrm{H}$ bond formation and hence $\mathrm{H}_{2}$ evolution. These insights have in turn motivated the exploration of many bioinspired structural and functional mimics bearing amines as the second sphere proton shuttles (Fig. 9a). ${ }^{125}$

Some of the most outstanding specimens of this approach are the [P2N2] Ni complexes from DuBois and lately, the Bullock team 
at Pacific Northwest National Laboratory. ${ }^{126}$ The [P2N2] ligands are bidentate and consist of two phosphines that the $\mathrm{Ni}$, with two pendant aryl or alkyl amines that serve as the proton shuttle (Fig. 9a). ${ }^{126}$ Each $\mathrm{Ni}$ complex binds two such [P2N2] ligands to form square planar [P2N2] ${ }_{2} \mathrm{Ni}^{\prime \prime}$ complexes. ${ }^{126}$ The Nill pre-catalysts can be sequentially reduced to $\mathrm{Ni}^{0}$ and protonated on the amines during electrocatalytic $\mathrm{H}_{2}$ evolution. ${ }^{126}$ Through a series of detailed mechanistic studies, it was found that the $\mathrm{Ni}$ complexes can cycle through five oxidation states from $\mathrm{Ni}^{0}$ up to $\mathrm{Ni}^{\mathrm{IV}}$ with the same ligand set. ${ }^{126}$ Most impressively, the variant with phenyl substituents on the amines can operate with TOF of $106,000 \mathrm{~s}^{-1}$ in

(a)<smiles>N#Cc1nc2c(nc1C#N)S[N+]1(S2)Sc2nc(C#N)c(C#N)nc2S1</smiles>

Protonation at pyrazine and ligandbased reduction only

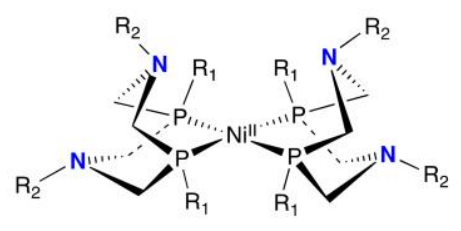

Amines act as efficient proton shuttle

$\mathrm{R}_{1}=\mathrm{Ph}$, cyclohexyl

$\mathrm{NR}_{2}=\mathrm{N}$-benzyl, glycine, arginine, $\mathrm{N}-\mathrm{Ph}$,
1.2 $\mathrm{M}$ water in acetonitrile, purportedly due to the position and $\mathrm{pK}_{\mathrm{a}}$ of the proton relay!127 In another functional parallel with [FeFe] hydrogenases, Shaw and coworkers installed arginines on the amine side-arms and showed that the new $\mathrm{Ni}$ electrocatalysts could oxidize $\mathrm{H}_{2}$ with TOF of $144,000 \mathrm{~s}^{-1}$, albeit at $133 \mathrm{~atm}$ of $\mathrm{H}_{2}$ and an overpotential of $460 \mathrm{mV}$ (Fig. 9a)..$^{128}$

Building upon the fantastic $\mathrm{H}_{2}$ evolution activity offered by the [P2N2] Nill catalysts, Reisner, Lotsch, and Durrant have incorporated them into photocatalytic systems using $\mathrm{Ru}$ and novel earthabundant material-based photosensitizers. Both purely molecular $\mathrm{Ru}$ and Ru-sensitized $\mathrm{TiO}_{2}$ were shown to be effective for
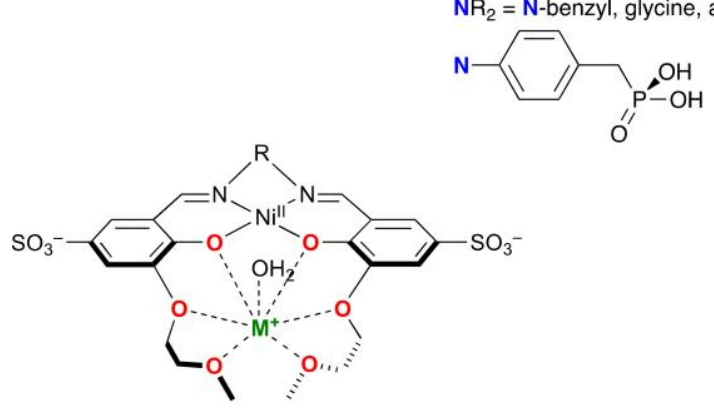

Ethers bind Lewis acids, e.g. alkali metal cations and serve as proton shuttle

$\mathrm{M}=\mathrm{Li}, \mathrm{Na}, \mathrm{K}$

(c)
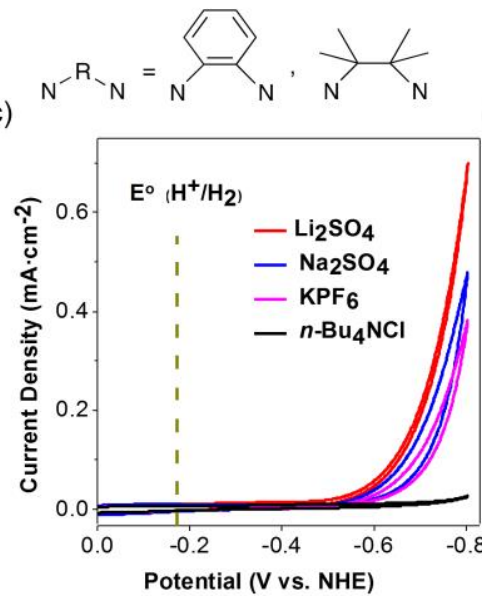

(d)
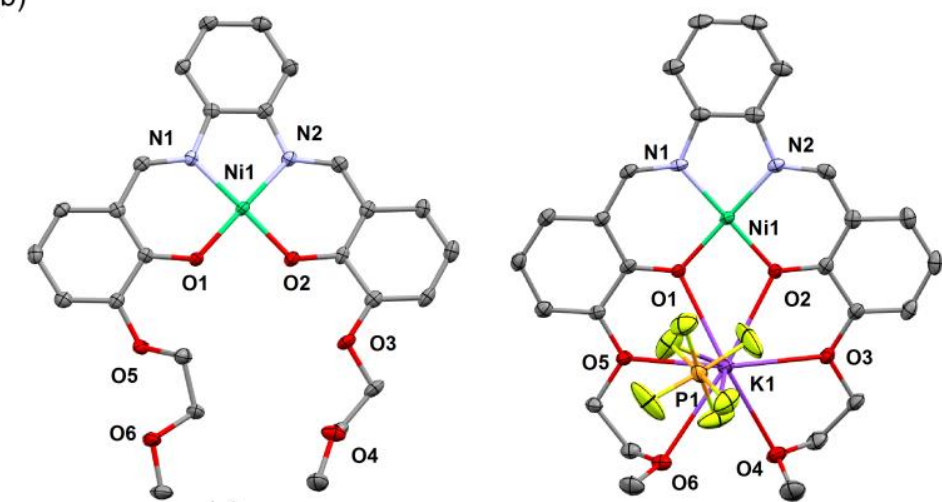

(e)

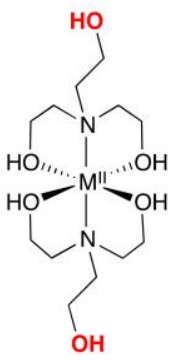

Alcohols provide hydrogen bonding and serve as proton shuttles

$\mathrm{M}=\mathrm{Fe}, \mathrm{Co}, \mathrm{Ni}$

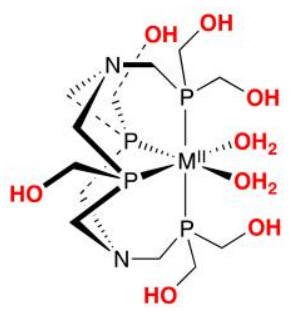

Alcohols provide hydrogen bonding and serve as proton shuttles

$\mathrm{M}=\mathrm{Fe}, \mathrm{Co}$
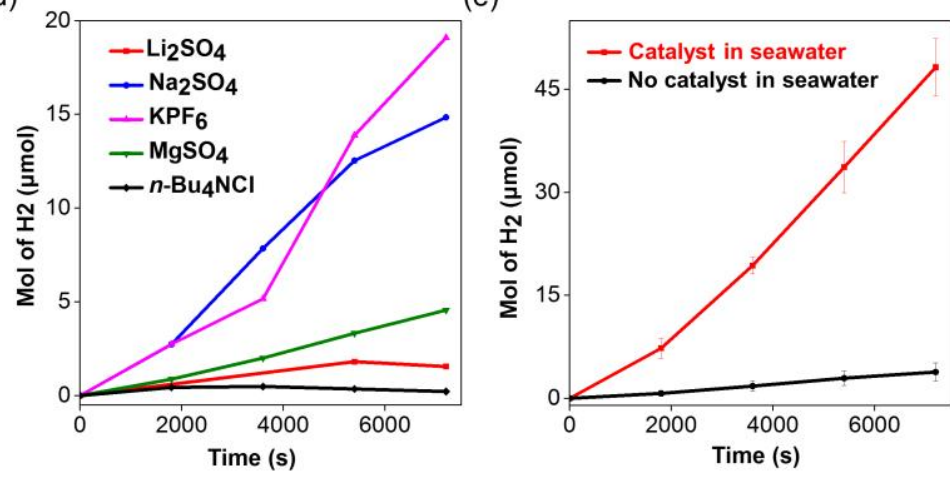

Fig. 9 (a) Recent examples using second-coordination sphere approaches to enhance $\mathrm{H}_{2}$ evolution catalysis. ${ }^{125-131,137-139}$ The features of each class of catalysts are emboldened and explained below the structure. (b) Crystal structure of the Ni" electrocatalysts possessing polyether chains without (left) and with $\mathrm{K}^{+}$cations developed by our team. Cyclic voltammetry (c) and controlled potential electrolysis (d) with our Nill catalyst comparing the effects of different electrolytes. (e) $\mathrm{H}_{2}$ evolution from seawater enhanced by our Lewis acid-binding $\mathrm{Ni}$ "l catalyst. The crystal structures and electrochemical data have been reproduced from reference 137. 
photocatalytic $\mathrm{H}_{2}$ evolution with photon-to- $\mathrm{H}_{2}$ quantum yields of up to $10 \% .129,130$ In related studies, carbon quantum dots and $\mathrm{CN}_{\mathrm{x}}$ materials were employed as the light absorbing and charge separating elements to achieve TONs above 1000 over several days. ${ }^{110,}{ }^{111}, 131$ These $\mathrm{H}_{2}$ evolution units represent some of the state-of-the-art in assembling the individually optimized components, exploiting vital second coordination sphere proton shuttle effects, into plug-and-play constructs.

In the same vein, the groups of Nam, Fukuzumi, ${ }^{132}$ and Agapie $^{133}$ discovered that redox inactive metals such as the alkaline earth elements, $\mathrm{Zn}^{\prime \prime}, \mathrm{Sc}^{\prime \prime \prime}$, and Y"II can be integrated into the second coordination sphere to fine-tune the redox properties and oxidative reactivity of high-valent $\mathrm{Mn}$ and Fe complexes. Motivated by these prior insights, our team sought a robust catalyst that could harness the abundance of alkali metal cations in seawater for proton reduction. The role of alkali metal cations as second sphere Lewis acids for binding $\mathrm{CO}_{2}$ in Co salophen and salicylaldimine ("salentype") complexes has been established since the 1970s. ${ }^{134-136}$ We considered if salen-type $\mathrm{Ni}$ complexes could be suitably modified with polyether chains to more effectively bind cations like $\mathrm{Na}^{+}$and $\mathrm{K}^{+}$that are ubiquitous in seawater. Gratifyingly, our $\mathrm{Ni}^{\prime \prime}$ complex decorated with methoxy-ethoxy chains at the ortho position of the phenoxy ring could indeed bind alkali metal cations, as verified by solid-state crystal structures and UV-visible measurements in solution (Fig. 9a and 9b). ${ }^{137}$ By using electrodes with high overpotentials for $\mathrm{H}_{2}$ evolution such as mercury pool and carbon paper, we observed with cyclic and linear sweep voltammetry that the catalytic current increased by a factor of 11 on going from tetrabutylammonium to lithium cations as the electrolyte (Fig. 9c). ${ }^{137}$ In addition, a similar enhancement was recorded during controlled potential electrolysis in both neutral and acetic acid aqueous solutions (Fig. 9d). Ultimately, $\mathrm{H}_{2}$ evolution from filtered seawater was quantified with Faradaic efficiencies of around $82 \%$ (Fig. 9e). ${ }^{137}$ Although seawater is typically more concentrated in electrolytes, it contains trace quantities of many ions that could poison catalysts, but not in our case. Our demonstration has thus highlighted a new approach to utilize second coordination sphere effects to encapsulate alkali metal cations and direct water molecules to be in close proximity with the redox-active catalytic center.

Another strategy adopted by Sun, Wang, and coworkers is to utilize hydrogen-bonding effects of peripheral alcohol groups to improve proton reduction catalysis. They discovered that $\mathrm{Fe}, \mathrm{Co}$, and $\mathrm{Ni}$ complexes formed in situ with triethanolamine (TEOA) as the ligand performed as stable $\mathrm{H}_{2}$ evolution catalysts (Fig. 9a). ${ }^{138}$ One of the arms of TEOA is not bound and could act as a hydrogen bond donor or proton donor. Using $\mathrm{CN}_{\mathrm{x}}$ as the visible-light photosensitizer, the activity of the $\mathrm{Ni}$ complex was sustained for at least 60 hours from unbuffered TEOA solutions. ${ }^{138}$ They extended this design principle to a different ligand set of tetraphoshines (" $\mathrm{P}_{4} \mathrm{~N}_{2}$ ") bearing several pendant alcohol groups (Fig. 9a). ${ }^{139}$ Remarkably, the in situ formed $\mathrm{CoP}_{4} \mathrm{~N}_{2}$ catalyst can operate with an onset potential of merely $80 \mathrm{mV}$ and has a TON of around 92,000 over $20 \mathrm{~h}$ in neutral phosphate buffer solutions. ${ }^{139}$ A series of control experiments including a rinse test and the use of mercury electrodes indicate that the catalytic activity is homogeneous. ${ }^{139}$
This catalytic system has in turn set a new landmark for high TONs and TOFs at low overpotentials, suggesting that thoughtfully designed molecular $\mathrm{H}_{2}$ evolution catalysts may eventually be competitive with Pt in fuel cells or other applications.

\subsection{Photocatalytic oxidation for solar chemicals}

The envisioned plug-and-play concept allows for a highly modular system in which a variety of oxidative and reductive half-reactions can be combined into suitable AP systems. Apart from the water oxidation reaction, which has been an integral part of many water splitting AP units, we aimed to investigate other photooxidative transformations that can supply electrons for the reductive halfreaction and result in value-added solar chemicals production. In this section, we will consider photocatalytic oxidation to achieve solar chemicals, with an emphasis on the use of earth-abundant constituents.

The water oxidation half-reaction is kinetically and thermodynamically challenging since it involves multiple electron and proton transfers, and usually produces $\mathrm{O}_{2}$, an abundant gas with limited commercial value. Hence, there have been some efforts to develop scalable oxidative half-reactions commensurate with the electron demand for solar fuels production. For instance, Meyer and co-workers have been adapting their DSPEC architecture to target the oxidation of earth-abundant halides, namely bromide

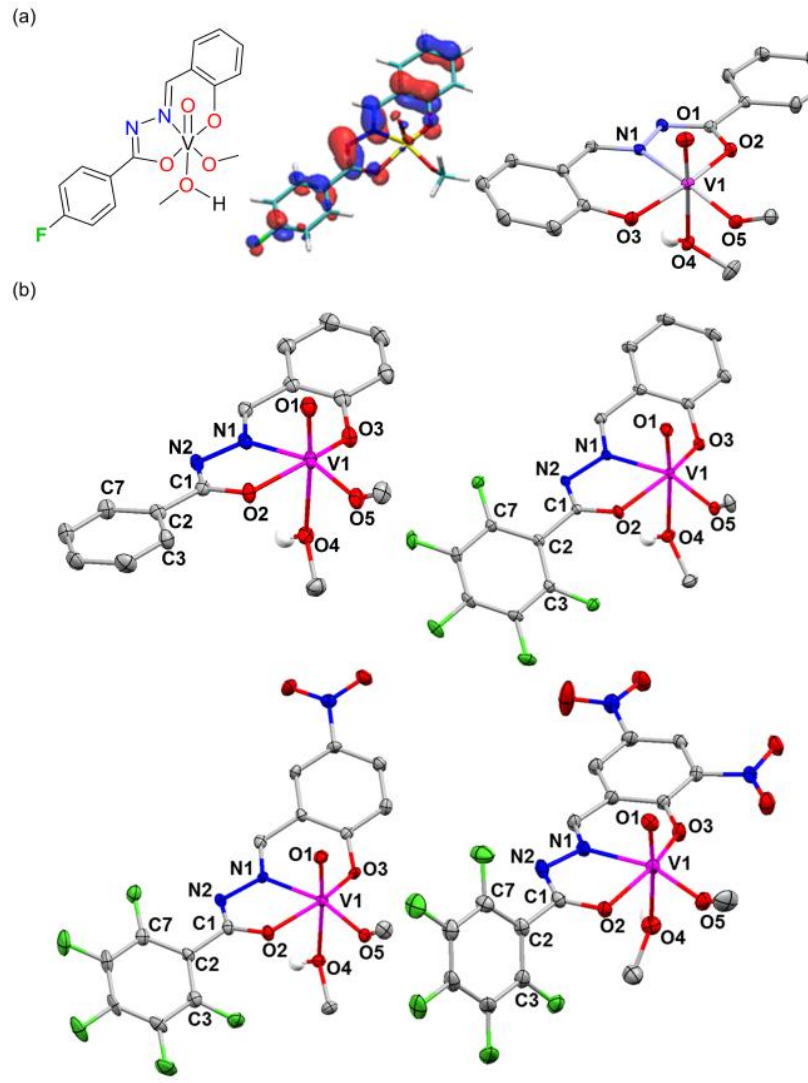

Fig. 10 (a) Structure (left), spatial distribution of HOMO (center), and crystal structure (right) of our original $\mathrm{V}^{\mathrm{V}}$ photocatalyst, adapted from reference 149. (b) Crystal structures of some of our faster and more robust $\mathrm{V} V$ photocatalysts containing $\mathrm{NO}_{2}$ and $\mathrm{F}$ substitutions. The ORTEPs have been adapted from reference 150 . 
and chloride. ${ }^{140,141}$ They employed cationic, visible light absorbing Rull polypyridyl photosensitizers and complexes to form ionic donor-acceptor interactions with halide ions and bring them in close proximity to the catalytic center. ${ }^{142}$ After the halide photooxidation reaction, the $\mathrm{X}_{2}$ molecules would be released due to the absence of Coulombic interactions. ${ }^{142}$ In the case of chloride oxidation, the reaction product was indirectly determined to be chlorine atoms via the use of 2,3-dimethyl-1,3-butadiene as a halogen trap. ${ }^{141}$ They have also applied their DSPEC for $\mathrm{HBr}$ splitting en route to the simultaneous generation of $\mathrm{H}_{2}$ as a solar fuel and $\mathrm{Br}_{2}$ and $\mathrm{Br}_{3}{ }^{-}$as solar chemicals. ${ }^{143}$ Notably, however, the DSPECs predominantly comprise Ru photosensitizers and catalysts, which will offer future opportunities for replacement with earth-abundant variants instead.

As another alternative to water oxidation, Reisner and coworkers have reported a system that replaced water oxidation with alcohol oxidation, and coupled it with $\mathrm{H}_{2}$ production to form an AP unit with concurrent solar chemicals and solar fuel generation. ${ }^{110}$ As introduced previously, a cyanamide surface-functionalized melontype $\mathrm{CN}_{\mathrm{x}}$ is the light harvester that oxidizes 4-methylbenzyl alcohol to the corresponding benzaldehyde through the photogenerated holes, while electrons are funnelled to a [P2N2] Nill catalyst, which performs as the $\mathrm{H}_{2}$ evolution catalyst. ${ }^{110}$ This study represents an outstanding integrated catalytic redox cycle free of expensive noble metals with almost $100 \%$ atom economy and yields value-added products for both half-reactions, showcasing the feasibility of accomplishing functional and effective AP using exclusively earthabundant elements. ${ }^{110}$

In some novel developments lately, there has been greater political and economic pressure to reduce our dependence on finite fossil fuels and harness the under-utilized but sizable quantities of biomass as renewable sources of carbon. Biomass is often treated as fuel currently, which destroys the inherent valuable functional groups in the original form. Moreover, the biomass-derived feedstocks produced in large scale often possess low value, which can be increased in further transformations. Thus, they represent suitable substrates for the oxidative half-reaction in AP constructs. In a recent study, Reisner and Kuehnel discussed the use of biomass lignocellulose for $\mathrm{H}_{2}$ production at room temperature and light irradiation in a photoreforming process. ${ }^{144,} 145$ Although the reduction half-reaction generates $\mathrm{H}_{2}$ cleanly as a fuel, the biomass oxidation half-reaction is unselective and predominantly yields $\mathrm{CO}_{2}$, which also presents opportunities to develop new processes to obtain more value-added feedstocks from non-food biomass. ${ }^{144,} 145$ For example, Sun and coworkers reported the oxidation of furfuryl alcohol and 5-hydroxymethylfurfural (HMF) coupled with a $\mathrm{H}_{2}$ evolution half-reaction using earth-abundant electrocatalysts. ${ }^{146,}, 147$ The reaction was conducted under strongly alkaline conditions and carboxylate products were obtained, of which 2,5-furandicarboxylic acid is a promising replacement for terephthalic acid in polyamides, polyurethanes, and polyesters. ${ }^{147}$ Their subsequent visible-light induced oxidative valorization of furfuryl alcohol and HMF over $\mathrm{Ni}$ (a)

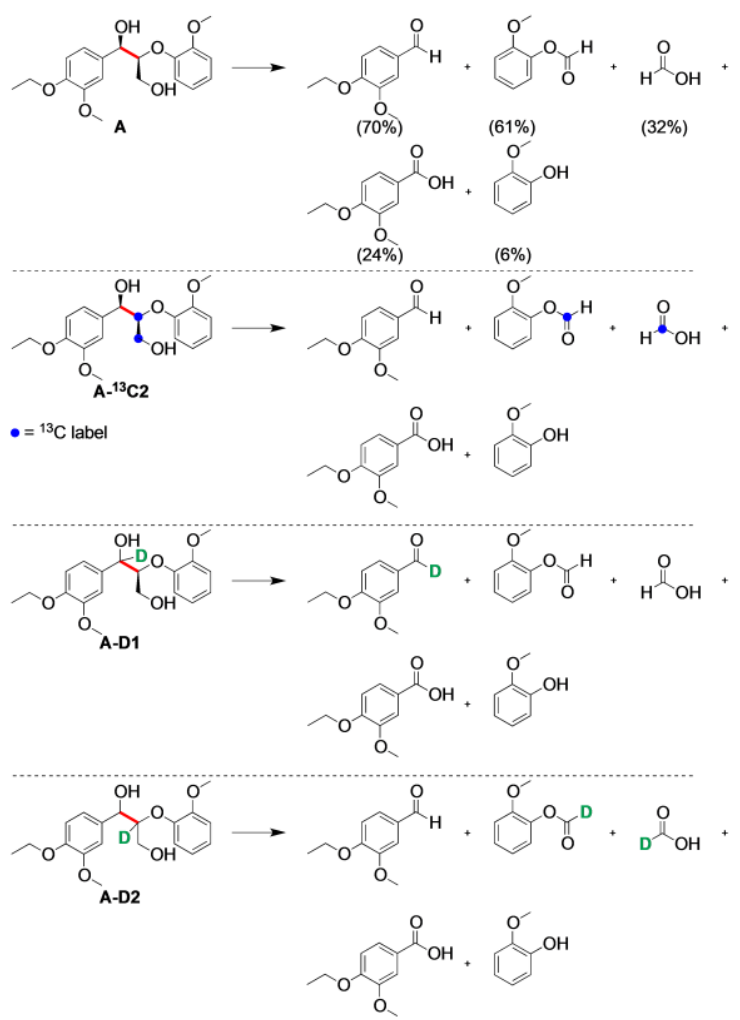

(b)

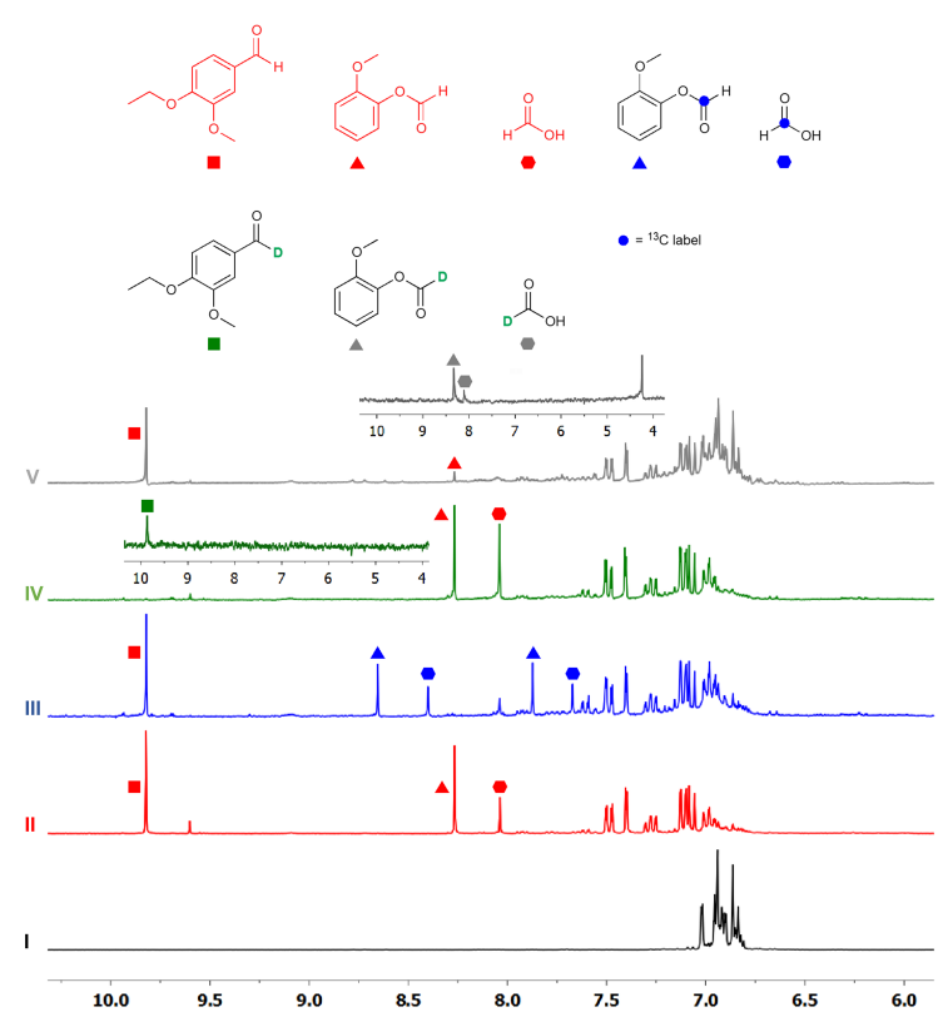

Fig. 11 (a) C-C bond cleavage of lignin model compound $\mathbf{A},{ }^{13} \mathrm{C}$-labeled $\mathbf{A}-{ }^{13} \mathbf{C} 2$, and the two deuterium labeled A-D1 and A-D2. The corresponding labeled products verify the absence of isotope scrambling, indicating that the benzylic alcohol oxidation to ketone did not occur prior or after the $\mathrm{C}-\mathrm{C}$ bond cleavage. (b) The ${ }^{1} \mathrm{H}$ and ${ }^{2} \mathrm{H}$ (insets) NMR spectra aiding our assignment of reaction products after $\mathrm{C}-\mathrm{C}$ bond cleavage: A before (I) and after $24 \mathrm{~h}$ irradiation (II); A-13 C2 after $24 \mathrm{~h}$ irradiation (III); A-D1 after $24 \mathrm{~h}$ irradiation (IV); and A-D2 after $24 \mathrm{~h}$ irradiation $(\mathrm{V})$. The data have been adapted from reference 149. 
decorated ultrathin CdS nanosheets in neutral water resulted in selective formation of value-added aldehyde or acid products, depending on the reaction conditions. ${ }^{148}$ Unfortunately, aldehydes appeared to inhibit the $\mathrm{Ni} / \mathrm{CdS}$ catalyst, which led to incomplete conversion of HMF. ${ }^{148}$ Nonetheless, their work is an important demonstration that biomass derived feedstocks can be upgraded to value-added aldehydes or acids, which are commonly used in the pharmaceutical and fragrance industries. This oxidative halfreaction produces more valuable solar chemicals than $\mathrm{O}_{2}$ from $\mathrm{H}_{2} \mathrm{O}$.

Bearing the versatile plug-and-play concept in mind, our group has been exploring the oxidation of non-food biomass lignin as another half-reaction in an AP system. Lignin, a sizable constituent of non-food biomass, is especially attractive since it represents one of the only renewable sources of aromatic compounds on Earth. However, although much effort has been devoted to the valorization of lignin into fuels through thermal and microbial reactions, majority of the valuable aromatic units and functional groups are destroyed. In our work on lignin model compounds, we have uncovered a unique $\mathrm{V}^{\mathrm{V}}$ photocatalyst (Fig. 10a) that is able to induce a highly selective and unprecedented $\mathrm{C}-\mathrm{C}$ bond scission in aliphatic alcohols under visible light irradiation and ambient, atmospheric conditions (Fig. 11 - 13). ${ }^{149}$ Surprisingly, the more common alcohol oxidation to ketones is not competitive since it occurs only at temperatures exceeding $80^{\circ} \mathrm{C} .{ }^{149}$

A number of representative lignin models were successfully screened for reactivity. ${ }^{149}$ Notably, the exceptionally mild and regioselective $\mathrm{C}-\mathrm{C}$ bond cleavage produced valuable aryl aldehyde and formate compounds in moderate to high yields. ${ }^{149}$ Detailed mechanistic studies and product analyses were conducted with the aid of ${ }^{2} \mathrm{H}$ and ${ }^{13} \mathrm{C}$ isotope labeling experiments, which revealed no isotope scrambling and alluded to an unusual pathway for direct C-
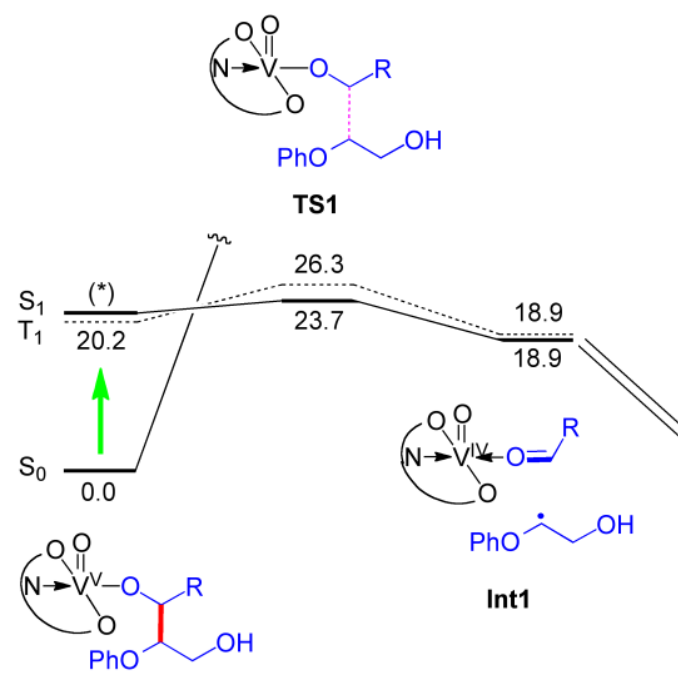

Int1

RC<smiles>[R]CO[N+]1(O)OCCO[N+]1(C)O</smiles>

Int2
C bond cleavage after photoexcitation (Fig. 11). ${ }^{149}$ Our experimental work was further supported by computational density functional theory (DFT) calculations which suggested that the $\mathrm{V}^{\mathrm{V}}$ photocatalyst was indeed capable of absorbing visible light via LMCT and trigger the unexpected $\mathrm{C}-\mathrm{C}$ bond cleavage adjacent to the alcohol group (TS1 in Fig. 12). ${ }^{149}$ This produced an aldehyde, while the resulting radical went on to react with $\mathrm{O}_{2}$ (Int1 and Int2 in Fig. 12) and eventually transformed into an oxygenated product such as formate. ${ }^{149}$

Following our initial success on the photooxidative C-C bond activation in aliphatic alcohols, we have improved upon our original design and developed a library of modified $\mathrm{V}^{\mathrm{V}}$ photocatalysts (Fig. 10b). ${ }^{150}$ By introducing strong electron-withdrawing groups such as $\mathrm{NO}_{2}$ and $\mathrm{F}$ at specific locations of the ligand where there is spin density on the HOMO (Fig. 10a), we were able to stabilize the HOMO energy level and increase the oxidative potential of the $\mathrm{V}$ photocatalyst. ${ }^{150}$ As anticipated, one of the more strongly oxidizing photocatalysts reacted up to 7 times faster than our earlier complex, although excessive substitution led to retarded reaction rates, likely because the catalyst was not as readily re-oxidized by $\mathrm{O}_{2} .{ }^{150}$

Furthermore, although our photocatalysts showed good reactivity with most of our original lignin model compounds, phenolic groups were not well tolerated. We surmised that the formate product in the lignin model compounds may have hydrolyzed into guaiacol, which may have poisoned the catalyst at high conversions. Thus, we prepared a new lignin model compound with one extra carbon so that the secondary hydrolysis product would be benzyl alcohol instead of a phenol (Fig. 13b). ${ }^{150}$ Remarkably, this new substrate underwent $\mathrm{C}-\mathrm{C}$ bond cleavage between 2.5 - 17 times faster, depending on the $\mathrm{V}^{\mathrm{V}}$ complex used,

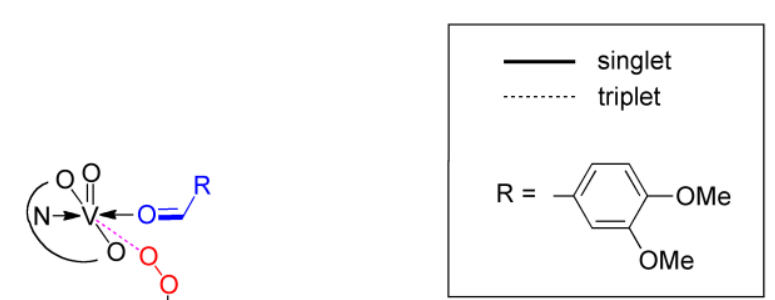<smiles>COC(CO)Oc1ccccc1</smiles>

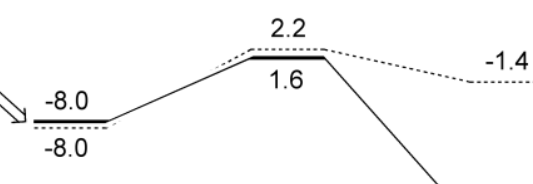

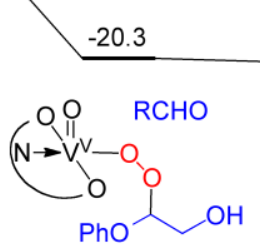

Int3

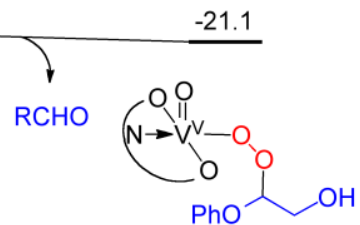

Int3'

Fig. 12 Proposed mechanism based on DFT calculations for our unusual C-C bond cleavage adjacent to the alcohol group without isotope scrambling, after LMCT photoexcitation of the $\mathrm{V}^{\mathrm{V}}$ catalyst. Note that the activation barrier of TS1 is merely $6.1 \mathrm{kcal}^{\mathrm{mol}}{ }^{-1}$, compared to a barrier of $20.2 \mathrm{kcal} \mathrm{mol}^{-1}$ for hydrogen atom abstraction from the benzylic position. The data have been adapted from reference 149. 
(a)
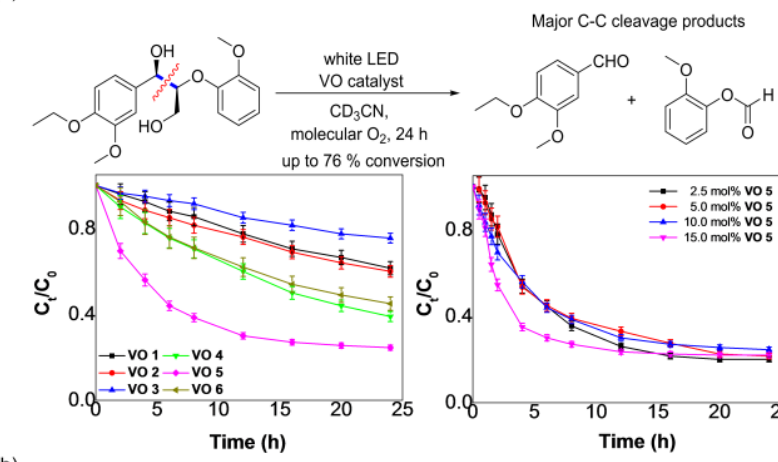

(b)

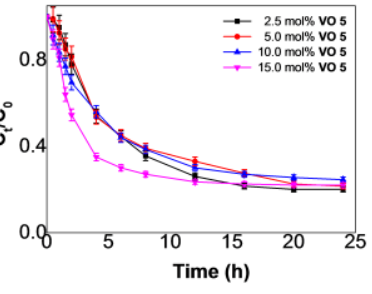

Major C-C cleavage products
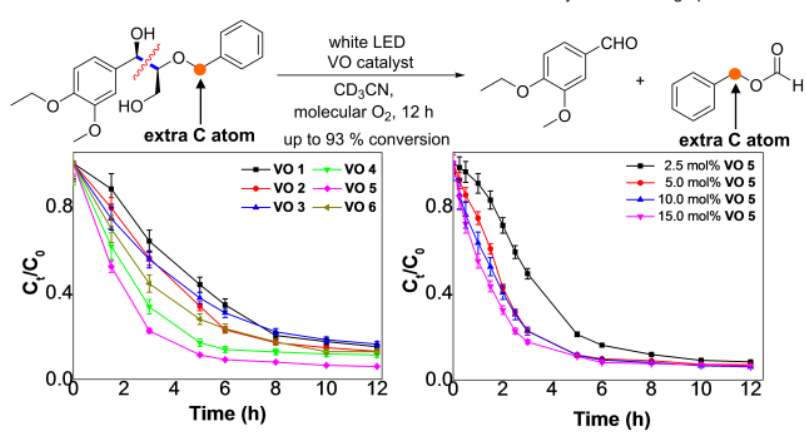

Fig. 13 Reaction scheme (top) and kinetics data (bottom) of the C$C$ bond cleavage reaction in our original lignin model compound (a) and the new lignin model compound with an extra carbon atom (b). The kinetics plots are depicted with substrate concentration decay over time with different catalysts at $10 \mathrm{~mol} \%$ loading (bottom left) and only the fastest catalyst at different loading levels (bottom right). The figures are adapted from reference 150 .

supporting our hypothesis that one of the catalyst deactivation pathways is through secondary phenolic product inhibition. ${ }^{150}$ Using thorough kinetics measurements (Fig. 13) and DFT studies, we were able to identify the fastest catalyst in our library, as well as gain insights into the choice of the optimal substrates for our unique $\mathrm{C}-\mathrm{C}$ bond cleavage reactivity. ${ }^{150}$

Although these studies are currently examined independently from the reductive half-reaction, we believe that this unusual C-C bond activation reaction is a suitable oxidative half-reaction candidate to plug into an AP system that would valorize biomass and other organic substrates to produce solar chemicals. Moreover, we hope to highlight its value for future research on LMCT induced $\mathrm{C}-\mathrm{C}$ bond activation by photocatalysts composed of earth-abundant elements, and also broaden the scope of feedstocks suitable for integrated AP.

\section{Outlook and concluding remarks}

Solar water splitting has often been considered as a "holy grail" of AP due to its significance and parallel to natural photosynthesis in generating solar fuels from abundant water. AP offers the versatility to store sunlight in energetic molecules without the need for batteries, allowing us to separate when we collect and use renewable energy. If it can be produced in a clean fashion in the reductive half-reaction from a sustainable, renewable, and abundant resource, $\mathrm{H}_{2}$ can be readily utilized as a fuel. It can be stored and used on demand, and reverts back to water upon oxidation, closing the cycle of generation and utilization of green energy. The water oxidation half-reaction, however, usually produces $\mathrm{O}_{2}$, which has only limited commercial value and can even form reactive oxygen species to damage the catalysts. Hence, a modular system that combines the desired reductive and oxidative halfreactions will be more flexible than a traditional water splitting process, which produces only $\mathrm{H}_{2}$ and $\mathrm{O}_{2}$.

In this feature article, we have highlighted the progress of our small but growing community in creating plug-and-play AP systems that can be used for the simultaneous production of solar fuels and solar chemicals in the two redox half-reactions. Such AP systems provide a number of benefits over water splitting. The oxidative process can potentially yield solar chemicals more valuable than $\mathrm{O}_{2}$ such as halogens (industrial disinfectants), polymer feedstocks, aromatic and carbonyl functionalized compounds, and even pharmaceutical precursors. Furthermore, through our experimental work on improving the catalyst design by kinetics measurements, understanding the deactivation pathways, and identifying the vital functional groups in substrates, we have demonstrated that a mild and selective $\mathrm{C}-\mathrm{C}$ bond activation in alcohols is a promising candidate for the oxidative half-reaction in AP. The fundamental studies have also paved the way for us to explore even more substrates and develop reusable catalysts. In addition, plug-and-play systems can be easier to develop and assemble. The main components of the system, including the the light harvester, charge mediator, reduction catalyst, and oxidation catalyst can all be independently optimized before being integrated into the desired AP system. It will also be amenable to high throughput screening and modern data analysis methods. We anticipate that our conceptual model will augment the field with numerous opportunities in each of the functional aspects discussed, and hope that AP will be a bedrock of the future global sustainable energy solution.

\section{Conflicts of interest}

There are no conflicts to declare.

\section{Acknowledgements}

HSS is supported by the Nanyang Assistant Professorship and MOE Tier 1 grants (M4011611 and M4011791). HSS also gratefully acknowledges the Agency for Science, Technology and Research (A*STAR), AME IRG grants A1783c0002 and A1783c0003, for funding this research. The authors acknowledge support from the Solar Fuels Lab at NTU and the SinBeRISE CREATE. Finally, the authors thank Prof. Sarifuddin Gazi, Dr. Jun Wei Kee, Dr. Haiyan Shao, Ms. Yik Yie Ng, and Ms. Jingyi Wang for contributing to the research. 


\section{Notes and references}

1. R. E. Smalley, MRS Bull., 2005, 30, 412-417.

2. S. Styring, Faraday Discuss., 2012, 155, 357-376.

3. M. Hambourger, G. F. Moore, D. M. Kramer, D. Gust, A. L. Moore and T. A. Moore, Chem. Soc. Rev., 2009, 38, 25-35.

4. G. F. Moore and G. W. Brudvig, Annu. Rev. Condens. Matter Phys., 2011, 2, 303-327.

5. E. M. Fischer and R. Knutti, Nat. Clim. Change, 2015, 5, 560564.

6. C. Lesk, P. Rowhani and N. Ramankutty, Nature, 2016, 529, 8487.

7. M. Calvin, Photochem. Photobiol., 1983, 37, 349-360.

8. D. Gust, T. A. Moore and A. L. Moore, Acc. Chem. Res., 2009, 42, 1890-1898.

9. I. McConnell, G. H. Li and G. W. Brudvig, Chem. Biol., 2010, 17, 434-447.

10. N. S. Lewis and D. G. Nocera, Proc. Natl. Acad. Sci. U.S.A., 2006, 103, 15729-15735.

11. N. S. Lewis, Science, 2016, 351.

12. T. A. Faunce, W. Lubitz, A. W. Rutherford, D. R. MacFarlane, G. F. Moore, P. D. Yang, D. G. Nocera, T. A. Moore, D. H. Gregory, S. Fukuzumi, K. B. Yoon, F. A. Armstrong, M. R. Wasielewski and S. Styring, Energy Environ. Sci., 2013, 6, 695-698.

13. F. E. Osterloh, ACS Energy Lett., 2017, 2, 445-453.

14. A. Fujishima and K. Honda, Nature, 1972, 238, 37-38.

15. O. Khaselev and J. A. Turner, Science, 1998, 280, 425-427.

16. S. Y. Reece, J. A. Hamel, K. Sung, T. D. Jarvi, A. J. Esswein, J. J. H. Pijpers and D. G. Nocera, Science, 2011, 334, 645-648.

17. Q. Wang, T. Hisatomi, Q. X. Jia, H. Tokudome, M. Zhong, C. Z. Wang, Z. H. Pan, T. Takata, M. Nakabayashi, N. Shibata, Y. B. Li, I. D. Sharp, A. Kudo, T. Yamada and K. Domen, Nat. Mater., 2016, 15, 611-615.

18. C. Liu, N. P. Dasgupta and P. D. Yang, Chem. Mater., 2014, 26, 415-422.

19. W. J. Ong, L. L. Tan, Y. H. Ng, S. T. Yong and S. P. Chai, Chem. Rev., 2016, 116, 7159-7329.

20. K. Sivula and R. van de Krol, Nat. Rev. Mater., 2016, 1.

21. G. Bottari, O. Trukhina, M. Ince and T. Torres, Coord. Chem. Rev., 2012, 256, 2453-2477.

22. S. Fukuzumi, K. Ohkubo and T. Suenobu, Acc. Chem. Res., 2014, 47, 1455-1464.

23. S. L. Gould, G. Kodis, R. E. Palacios, L. de la Garza, A. Brune, D. Gust, T. A. Moore and A. L. Moore, J. Phys. Chem. B, 2004, 108, 10566-10580.

24. Y. Nakamura, N. Aratani and A. Osuka, Chem. Soc. Rev., 2007, 36, 831-845.

25. D. L. Ashford, M. K. Gish, A. K. Vannucci, M. K. Brennaman, J. L. Templeton, J. M. Papanikolas and T. J. Meyer, Chem. Rev., 2015, 115, 13006-13049.

26. B. Pashaei, H. Shahroosvand, M. Graetzel and M. K. Nazeeruddin, Chem. Rev., 2016, 116, 9485-9564.

27. J. R. Swierk and T. E. Mallouk, Chem. Soc. Rev., 2013, 42, 23572387.

28. N. Armaroli, Chem. Soc. Rev., 2001, 30, 113-124.

29. M. Abrahamsson, M. Jager, R. J. Kumar, T. Osterman, P. Persson, H. C. Becker, O. Johansson and L. Hammarstrom, J. Am. Chem. Soc., 2008, 130, 15533-15542.

30. D. G. Brown, N. Sanguantrakun, B. Schulze, U. S. Schubert and C. P. Berlinguette, J. Am. Chem. Soc., 2012, 134, 12354-12357.
31. P. Chabera, Y. Z. Liu, O. Prakash, E. Thyrhaug, A. El Nahhas, A. Honarfar, S. Essen, L. A. Fredin, T. C. B. Harlang, K. S. Kjaer, K. Handrup, F. Ericson, H. Tatsuno, K. Morgan, J. Schnadt, L. Haggstrom, T. Ericsson, A. Sobkowiak, S. Lidin, P. Huang, S. Styring, J. Uhlig, J. Bendix, R. Lomoth, V. Sundstrom, P. Persson and K. Warnmark, Nature, 2017, 543, 695-699.

32. E. A. Juban, A. L. Smeigh, J. E. Monat and J. K. McCusker, Coord. Chem. Rev., 2006, 250, 1783-1791.

33. S. M. Fatur, S. G. Shepard, R. F. Higgins, M. P. Shores and N. H. Damrauer, J. Am. Chem. Soc., 2017, 139, 4493-4505.

34. S. G. Shepard, S. M. Fatur, A. K. Rappe and N. H. Damrauer, J. Am. Chem. Soc., 2016, 138, 2949-2952.

35. T. C. B. Harlang, Y. Z. Liu, O. Gordivska, L. A. Fredin, C. S. Ponseca, P. Huang, P. Chabera, K. S. Kjaer, H. Mateos, J. Uhlig, R. Lomoth, R. Wallenberg, S. Styring, P. Persson, V. Sundstrom and K. Warnmark, Nat. Chem., 2015, 7, 883-889.

36. R. F. Higgins, S. M. Fatur, S. G. Shepard, S. M. Stevenson, D. J. Boston, E. M. Ferreira, N. H. Damrauer, A. K. Rappe and M. P. Shores, J. Am. Chem. Soc., 2016, 138, 5451-5464.

37. C. Wang, S. Otto, M. Dorn, E. Kreidt, J. Lebon, L. Srsan, P. Di Martino-Fumo, M. Gerhards, U. Resch-Genger, M. Seitz and K. Heinze, Angew. Chem. Int. Ed., 2018, 57, 1112-1116.

38. L. A. Buldt, X. W. Guo, R. Vogel, A. Prescimone and O. S. Wenger, J. Am. Chem. Soc., 2017, 139, 985-992.

39. X. Q. Lu, S. X. Wei, C. M. L. Wu, S. R. Li and W. Y. Guo, J. Phys. Chem. C, 2011, 115, 3753-3761.

40. C. E. McCusker and F. N. Castellano, Inorg. Chem., 2013, 52, 8114-8120.

41. L. X. Chen, G. B. Shaw, I. Novozhilova, T. Liu, G. Jennings, K. Attenkofer, G. J. Meyer and P. Coppens, J. Am. Chem. Soc., 2003, 125, 7022-7034.

42. M. Iwamura, S. Takeuchi and T. Tahara, Acc. Chem. Res., 2015, 48, 782-791.

43. S. Garakyaraghi, P. D. Crapps, C. E. McCusker and F. N. Castellano, Inorg. Chem., 2016, 55, 10628-10636.

44. S. Garakyaraghi, E. O. Danilov, C. E. McCusker and F. N. Castellano, J. Phys. Chem. A, 2015, 119, 3181-3193.

45. S. Garakyaraghi, P. Koutnik and F. N. Castellano, Phys. Chem. Chem. Phys., 2017, 19, 16662-16668.

46. R. S. Khnayzer, C. E. McCusker, B. S. Olaiya and F. N. Castellano, J. Am. Chem. Soc., 2013, 135, 14068-14070.

47. M. S. Lazorski and F. N. Castellano, Polyhedron, 2014, 82, $57-$ 70.

48. C. E. McCusker and F. N. Castellano, Inorg. Chem., 2015, 54, 6035-6042.

49. M. Pirtsch, S. Paria, T. Matsuno, H. Isobe and O. Reiser, Chem. Eur. J., 2012, 18, 7336-7340.

50. J. M. Ahn, T. S. Ratani, K. I. Hannoun, G. C. Fu and J. C. Peters, J. Am. Chem. Soc., 2017, 139, 12716-12723.

51. Q. M. Kainz, C. D. Matier, A. Bartoszewicz, S. L. Zultanski, J. C. Peters and G. C. Fu, Science, 2016, 351, 681-684.

52. W. Zhao, R. P. Wurz, J. C. Peters and G. C. Fu, J. Am. Chem. Soc., 2017, 139, 12153-12156.

53. J. W. Kee, Y. Y. Ng, S. A. Kulkarni, S. K. Muduli, K. Xu, R. Ganguly, Y. Lu, H. Hirao and H. S. Soo, Inorg. Chem. Front., 2016, 3, 651-662.

54. T. Kern, U. Monkowius, M. Zabel and G. Knor, Eur. J. Inorg. Chem., 2010, 4148-4156.

55. P. Papanikolaou, P. D. Akrivos, A. Czapik, B. Wicher, M. Gdaniec and N. Tkachenko, Eur. J. Inorg. Chem., 2013, 24182431. 
56. P. A. Papanikolaou and N. V. Tkachenko, Phys. Chem. Chem. Phys., 2013, 15, 13128-13136.

57. I. L. Fedushkin, A. A. Skatova, V. K. Cherkasov, V. A. Chudakova, S. Dechert, M. Hummert and H. Schumann, Chem. Eur. J., 2003, 9, 5778-5783.

58. N. J. Hill, I. Vargas-Baca and A. H. Cowley, Dalton Trans., 2009, 240-253.

59. J. Wang, R. Ganguly, Y. Li, J. Diaz, H. S. Soo and F. Garcia, Dalton Trans., 2016, 45, 7941-7946.

60. J. Wang, R. Ganguly, Y. Li, J. Diaz, H. S. Soo and F. Garcia, Inorg. Chem., 2017, 56, 7811-7820.

61. K. Hasan and E. Zysman-Colman, Inorg. Chem., 2012, 51, 12560-12564.

62. K. Hasan and E. Zysman-Colman, Eur. J. Inorg. Chem., 2013, 2013, 4421-4429.

63. K. Hasan and E. Zysman-Colman, J. Phys. Org. Chem., 2013, 26, 274-279.

64. K. Hasan, J. Wang, A. K. Pal, C. Hierlinger, V. Guerchais, H. S. Soo, F. Garcia and E. Zysman-Colman, Sci. Rep., 2017, 7, 15520.

65. A. Dolbecq, P. Mialane, B. Keita and L. Nadjo, J. Mater. Chem. 2012, 22, 24509-24521.

66. J. W. Zhao, Y. Z. Li, L. J. Chen and G. Y. Yang, Chem. Commun., 2016, 52, 4418-4445.

67. J. J. Walsh, A. M. Bond, R. J. Forster and T. E. Keyes, Coord. Chem. Rev., 2016, 306, 217-234.

68. M. L. Macnaughtan, H. S. Soo and H. Frei, J. Phys. Chem. C, 2014, 118, 7874-7885.

69. H. S. Soo, M. L. Macnaughtan, W. W. Weare, J. Yano and H. Frei, J. Phys. Chem. C, 2011, 115, 24893-24905.

70. G. Blasse, in Structure \& Bonding, Springer Berlin Heidelberg, 1991, vol. 76, pp. 153-187.

71. H. Frei, Chimia, 2009, 63, 721-730.

72. H. Frei, J. Energy Chem., 2017, 26, 241-249.

73. T. Cuk, W. W. Weare and H. Frei, J. Phys. Chem. C, 2010, 114, 9167-9172.

74. H. X. Han and H. Frei, Microporous Mesoporous Mater., 2007, 103, 265-272.

75. H. X. Han and H. Frei, J. Phys. Chem. C, 2008, 112, 1615616159.

76. H. X. Han and H. Frei, J. Phys. Chem. C, 2008, 112, 8391-8399.

77. W. Kim, E. Edri and H. Frei, Acc. Chem. Res., 2016, 49, 16341645.

78. W. Kim and H. Frei, ACS Catal., 2015, 5, 5627-5635.

79. W. Kim, G. Yuan, B. A. McClure and H. Frei, J. Am. Chem. Soc., 2014, 136, 11034-11042.

80. W. Y. Lin and H. Frei, J. Phys. Chem. B, 2005, 109, 4929-4935.

81. W. Y. Lin and H. Frei, J. Am. Chem. Soc., 2005, 127, 1610-1611.

82. B. A. McClure and H. Frei, J. Phys. Chem. C, 2014, 118, 1160111611.

83. X. N. Wu, W. W. Weare and H. Frei, Dalton Trans., 2009, 10114-10121.

84. R. Nakamura, A. Okamoto, H. Osawa, H. Irie and K. Hashimoto, J. Am. Chem. Soc., 2007, 129, 9596-9597.

85. K. Hu, A. D. Blair, E. J. Piechota, P. A. Schauer, R. N. Sampaio, F. G. L. Parlane, G. J. Meyer and C. P. Berlinguette, Nat. Chem., 2016, 8, 853-859.

86. R. L. Milot and C. A. Schmuttenmaer, Acc. Chem. Res., 2015, 48, 1423-1431.

87. S. C. Lian, D. J. Weinberg, R. D. Harris, M. S. Kodaimati and E. A. Weiss, ACS Nano, 2016, 10, 6372-6382.

88. S. P. Pujari, L. Scheres, A. T. M. Marcelis and H. Zuilhof, Angew. Chem. Int. Ed., 2014, 53, 6322-6356.
89. C. Queffelec, M. Petit, P. Janvier, D. A. Knight and B. Bujoli, Chem. Rev., 2012, 112, 3777-3807.

90. A. M. Beiler, D. Khusnutdinova, S. I. Jacob and G. F. Moore, ACS Appl. Mater. Inter., 2016, 8, 10038-10047.

91. A. M. Beiler, D. Khusnutdinova, B. L. Wadsworth and G. F. Moore, Inorg. Chem., 2017, 56, 12178-12185.

92. D. Khusnutdinova, A. M. Beiler, B. L. Wadsworth, S. I. Jacob and G. F. Moore, Chem. Sci., 2017, 8, 253-259.

93. A. Krawicz, J. H. Yang, E. Anzenberg, J. Yano, I. D. Sharp and G. F. Moore, J. Am. Chem. Soc., 2013, 135, 11861-11868.

94. B. L. Wadsworth, A. M. Beiler, D. Khusnutdinova, S. I. Jacob and G. F. Moore, ACS Catal., 2016, 6, 8048-8057.

95. D. Cedeno, A. Krawicz, P. Doak, M. Yu, J. B. Neaton and G. F. Moore, J. Phys. Chem. Lett., 2014, 5, 3222-3226.

96. T. Fukushima, W. Drisdell, J. Yano and Y. Surendranath, J. Am. Chem. Soc., 2015, 137, 10926-10929.

97. N. D. Ricke, A. T. Murray, J. J. Shepherd, M. G. Welborn, T. Fukushima, T. Van Voorhis and Y. Surendranath, ACS Catal., 2017, 7, 7680-7687.

98. S. Oh, J. R. Gallagher, J. T. Miller and Y. Surendranath, J. Am. Chem. Soc., 2016, 138, 1820-1823.

99. M. N. Jackson, S. Oh, C. J. Kaminsky, S. B. Chu, G. Zhang, J. T. Miller and Y. Surendranath, J. Am. Chem. Soc., 2018, 140, 1004-1010.

100. M. T. Huynh, S. J. Mora, M. Villalba, M. E. Tejeda-Ferrari, P. A. Liddell, B. R. Cherry, A. L. Teillout, C. W. Machan, C. P. Kubiak, D. Gust, T. A. Moore, S. Hammes-Schiffer and A. L. Moore, ACS Cent. Sci., 2017, 3, 372-380.

101. S. J. Mora, E. Odella, G. F. Moore, D. Gust, T. A. Moore and A. L. Moore, Acc. Chem. Res., 2018, 51, 445-453.

102. Y. Terazono, G. Kodis, K. Bhushan, J. Zaks, C. Madden, A. L. Moore, T. A. Moore, G. R. Fleming and D. Gust, J. Am. Chem. Soc., 2011, 133, 2916-2922.

103. L. Hammarstrom, Acc. Chem. Res., 2015, 48, 840-850.

104. A. M. Brown, L. J. Antila, M. Mirmohades, S. Pullen, S. Ott and L. Hammarstrom, J. Am. Chem. Soc., 2016, 138, 8060-8063.

105. Y. C. Gong, D. P. Wang, R. B. Wu, S. Gazi, H. S. Soo, T. Sritharan and Z. Chen, Dalton Trans., 2017, 46, 4994-5002.

106. T. M. Koh, K. Thirumal, H. S. Soo and N. Mathews, ChemSusChem, 2016, 9, 2541-2558.

107. S. K. Muduli, S. L. Wang, S. Chen, C. F. Ng, C. H. A. Huan, T. C. Sum and H. S. Soo, Beilstein J. Nanotechnol., 2014, 5, 517-523.

108. K. Thirumal, W. K. Chong, W. Xie, R. Ganguly, S. K. Muduli, M. Sherburne, M. Asta, S. Mhaisalkar, T. C. Sum, H. S. Soo and N. Mathews, Chem. Mater., 2017, 29, 3947-3953.

109. X. C. Wang, K. Maeda, X. F. Chen, K. Takanabe, K. Domen, Y. D. Hou, X. Z. Fu and M. Antonietti, J. Am. Chem. Soc., 2009, 131, 1680-1681.

110. H. Kasap, C. A. Caputo, B. C. M. Martindale, R. Godin, V. W. H. Lau, B. V. Lotsch, J. R. Durrant and E. Reisner, J. Am. Chem. Soc., 2016, 138, 9183-9192.

111. B. C. M. Martindale, E. Joliat, C. Bachmann, R. Alberto and E. Reisner, Angew. Chem. Int. Ed., 2016, 55, 9402-9406.

112. V. W. H. Lau, D. Klose, H. Kasap, F. Podjaski, M. C. Pignie, E. Reisner, G. Jeschke and B. V. Lotsch, Angew. Chem. Int. Ed., 2017, 56, 510-514.

113. F. Jiao and H. Frei, Angew. Chem. Int. Ed., 2009, 48, 1841-1844.

114. H. S. Soo, A. Agiral, A. Bachmeier and H. Frei, J. Am. Chem. Soc., 2012, 134, 17104-17116.

115. A. Agiral, H. S. Soo and H. Frei, Chem. Mater., 2013, 25, 22642273.

116. E. Edri and H. Frei, J. Phys. Chem. C, 2015, 119, 28326-28334. 
117. E. Edri, J. K. Cooper, I. D. Sharp, D. M. Guldi and H. Frei, J. Am. Chem. Soc., 2017, 139, 5458-5466.

118. E. Edri, S. Aloni and H. Frei, ACS Nano, 2018, 12, 533-541.

119. M. Zeng and Y. G. Li, J. Mater. Chem. A, 2015, 3, 14942-14962.

120. P. C. K. Vesborg, B. Seger and I. Chorkendorff, J. Phys. Chem. Lett., 2015, 6, 951-957.

121. D. Voiry, H. S. Shin, K. P. Loh and M. Chhowalla, Nat. Rev. Chem., 2018, 2.

122. V. S. Thoi, Y. J. Sun, J. R. Long and C. J. Chang, Chem. Soc. Rev., 2013, 42, 2388-2400.

123. D. Z. Zee, T. Chantarojsiri, J. R. Long and C. J. Chang, Acc. Chem. Res., 2015, 48, 2027-2036.

124. J. C. Fontecilla-Camps, A. Volbeda, C. Cavazza and Y. Nicolet, Chem. Rev., 2007, 107, 4273-4303.

125. K. Koshiba, K. Yamauchi and K. Sakai, Angew. Chem. Int. Ed., 2017, 56, 4247-4251.

126. M. R. Dubois and D. L. Dubois, Acc. Chem. Res., 2009, 42, 19741982.

127. M. L. Helm, M. P. Stewart, R. M. Bullock, M. R. DuBois and D. L. DuBois, Science, 2011, 333, 863-866.

128. A. Dutta, J. A. S. Roberts and W. J. Shaw, Angew. Chem. Int. Ed., 2014, 53, 6487-6491.

129. M. A. Gross, A. Reynal, J. R. Durrant and E. Reisner, J. Am. Chem. Soc., 2014, 136, 356-366.

130. A. Reynal, E. Pastor, M. A. Gross, S. Selim, E. Reisner and J. R. Durrant, Chem. Sci., 2015, 6, 4855-4859.

131. C. A. Caputo, M. A. Gross, V. W. Lau, C. Cavazza, B. V. Lotsch and E. Reisner, Angew. Chem. Int. Ed., 2014, 53, 11538-11542.

132. S. Bang, Y. M. Lee, S. Hong, K. B. Cho, Y. Nishida, M. S. Seo, R. Sarangi, S. Fukuzumi and W. Nam, Nat. Chem., 2014, 6, 934940.

133. E. Y. Tsui, R. Tran, J. Yano and T. Agapie, Nat. Chem., 2013, 5, 293-299.

134. C. Floriani and Fachinet.G, J. Chem. Soc. Chem. Commun., 1974, 615-616.

135. G. Fachinetti, C. Floriani and P. F. Zanazzi, J. Am. Chem. Soc., 1978, 100, 7405-7407.

136. S. Gambarotta, F. Arena, C. Floriani and P. F. Zanazzi, J. Am. Chem. Soc., 1982, 104, 5082-5092.

137. H. Shao, S. K. Muduli, P. D. Tran and H. S. Soo, Chem. Commun., 2016, 52, 2948-2951.

138. J. F. Dong, M. Wang, X. Q. Li, L. Chen, Y. He and L. C. Sun, ChemSusChem, 2012, 5, 2133-2138.

139. L. Chen, M. Wang, K. Han, P. L. Zhang, F. Gloaguen and L. C. Sun, Energy Environ. Sci., 2014, 7, 329-334.

140. G. C. Li, W. M. Ward and G. J. Meyer, J. Am. Chem. Soc., 2015, 137, 8321-8323.

141. S. A. M. Wehlin, L. Troian-Gautier, G. C. Li and G. J. Meyer, J. Am. Chem. Soc., 2017, 139, 12903-12906.

142. G. C. Li, W. B. Swords and G. J. Meyer, J. Am. Chem. Soc., 2017, 139, 14983-14991.

143. M. D. Brady, R. N. Sampaio, D. G. Wang, T. J. Meyer and G. J. Meyer, J. Am. Chem. Soc., 2017, 139, 15612-15615.

144. M. F. Kuehnel and E. Reisner, Angew. Chem. Int. Ed. 2018, 57, 3290-3296.

145. D. W. Wakerley, M. F. Kuehnel, K. L. Orchard, K. H. Ly, T. E. Rosser and E. Reisner, Nat. Energy, 2017, 2.

146. B. You, N. Jiang, X. Liu and Y. J. Sun, Angew. Chem. Int. Ed., 2016, 55, 9913-9917.

147. B. You, X. Liu, N. Jiang and Y. J. Sun, J. Am. Chem. Soc., 2016, 138, 13639-13646.
148. G. Q. Han, Y. H. Jin, R. A. Burgess, N. E. Dickenson, X. M. Cao and Y. J. Sun, J. Am. Chem. Soc., 2017, 139, 15584-15587.

149. S. Gazi, W. K. H. Ng, R. Ganguly, A. M. P. Moeljadi, H. Hirao and H. S. Soo, Chem. Sci., 2015, 6, 7130-7142.

150. S. Gazi, M. Dokic, A. M. P. Moeljadi, R. Ganguly, H. Hirao and H. S. Soo, ACS Catal., 2017, 7, 4682-4691. 